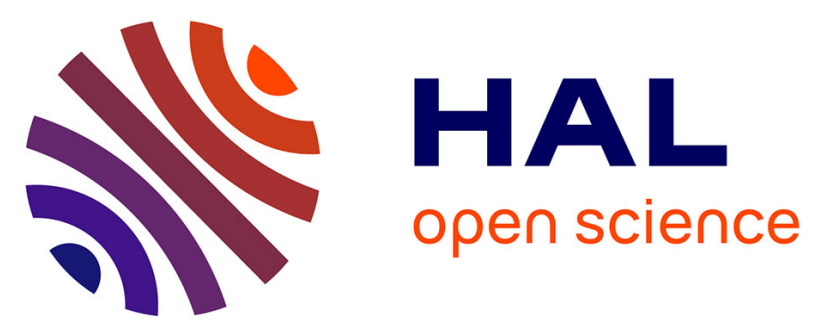

\title{
Ultrafast Dynamics of Metal Complexes of Tetrasulfonated Phthalocyanines at Biological Interfaces: Comparison between Photochemistry in Solutions, Films, and Noncancerous and Cancerous Human Breast Tissues
}

Halina Abramczyk, Beata Brozek-Pluska, Marc Tondusson, Eric Freysz

\section{To cite this version:}

Halina Abramczyk, Beata Brozek-Pluska, Marc Tondusson, Eric Freysz. Ultrafast Dynamics of Metal Complexes of Tetrasulfonated Phthalocyanines at Biological Interfaces: Comparison between Photochemistry in Solutions, Films, and Noncancerous and Cancerous Human Breast Tissues. Journal of Physical Chemistry C, 2013, 117 (10), pp.4999-5013. 10.1021/jp305891p . hal-00814211

\author{
HAL Id: hal-00814211 \\ https://hal.science/hal-00814211
}

Submitted on 27 Feb 2018

HAL is a multi-disciplinary open access archive for the deposit and dissemination of scientific research documents, whether they are published or not. The documents may come from teaching and research institutions in France or abroad, or from public or private research centers.
L'archive ouverte pluridisciplinaire HAL, est destinée au dépôt et à la diffusion de documents scientifiques de niveau recherche, publiés ou non, émanant des établissements d'enseignement et de recherche français ou étrangers, des laboratoires publics ou privés.

\section{(ㅇ)(1) $\$$}

Distributed under a Creative Commons Attribution - NonCommerciall 4.0 International 


\title{
Ultrafast Dynamics of Metal Complexes of Tetrasulfonated Phthalocyanines at Biological Interfaces: Comparison between Photochemistry in Solutions, Films, and Noncancerous and Cancerous Human Breast Tissues
}

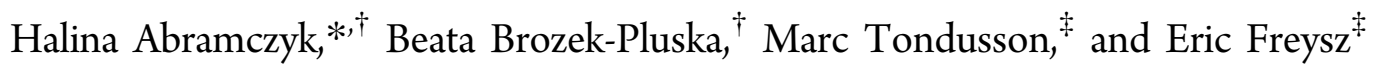 \\ ${ }^{\dagger}$ Institute of Applied Radiation Chemistry, Laboratory of Laser Molecular Spectroscopy, Lodz University of Technology, \\ Wroblewskiego 15, 93590 Lodz, Poland \\ ${ }^{\ddagger}$ Laboratoire Ondes et Matière d'Aquitaine (LOMA), UMR CNRS 5798, Université Bordeaux 1, 351 Cours de la Libération 33405 \\ Talence Cedex, France
}

\begin{abstract}
A promising material in medicine, electronics, opto electronics, electrochemistry, catalysis, and photophysics, $\mathrm{Al}(\mathrm{III})$ phthalocyanine chloride tetrasulfonic acid $\left(\mathrm{AlPcS}_{4}\right)$ is investigated at biological interfaces of human breast tissue by means of steady state and time resolved pump-probe spectroscopies: IR, Raman, UV-vis, fluorescence, and electronic transient absorption by pump-probe spectroscopy. Spectrally resolved pump-probe data were recorded on time scales ranging from femtoseconds to nanoseconds and give insight into molecular interactions and primary events in the interfacial region. The nature of these fast processes and pathways of the competing relaxation processes from the initially excited electronic states in $\mathrm{AlPcS}_{4}$ films and at biological interfaces of human breast cancerous and noncancerous tissues is studied. Comparison between photochemical dynamics in the biological environment of the human breast tissues and that occurring in aqueous solutions is presented. The excited state absorption (ESA) decays and

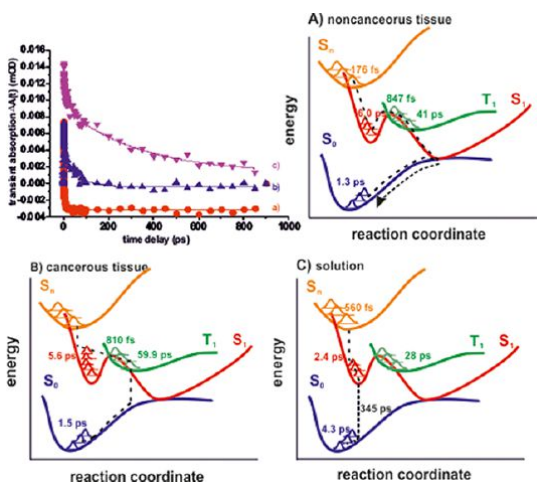

bleaching recovery of the ground state have been fitted in the time window extending to nanoseconds $(0-1 \mathrm{~ns})$. We found that the excited state dynamics of $\mathrm{AlPcS}_{4}$ at biological interfaces of human breast tissue is extremely sensitive to the biological environment and differs drastically from that observed in solutions and films. We demonstrated that the ultrafast dynamics at biological interfaces is described by three time constants in the ranges of $110-170 \mathrm{fs}$, 1-7 ps, and 20-60 ps. We were able to ascribe these three time constants to the primary events occurring in phthalocyanine at biological interfaces. The shortest time constants have been assigned to vibrational wavepacket dynamics in the Franck-Condon region down to the local minimum of the excited state $S_{1}$. The 1-7 ps components have been assigned to vibrational relaxation in the excited and ground electronic states. In contrast to the dynamics observed in aqueous solutions with the components in the range of 150-500 ps assigned to decay from $S_{1}$ to the ground electronic state, these slow components have not been recorded in human breast tissue. We have shown that the lifetimes characterizing the first excited state $S_{1}$ in the interfacial regions of the breast tissue are markedly shorter than those in solution. It suggests that molecular structures responsible for harvesting of the light energy in biological tissue find their own ways for recovery through some special features of the potential energy surfaces such as conical intersections, which facilitate the rate of radiationless transitions. We found that the dynamics of photosensitizers in normal (noncancerous) breast tissue is markedly faster than that in cancerous tissue.
\end{abstract}

\section{INTRODUCTION}

Phthalocyanines are promising materials in medicine, elec tronics, opto electronics, electrochemistry, and catalysis. The growing numbers of phthalocyanines play an important role as photosensitizers in photodynamic therapy (PDT), inactivation of antibiotic resistant microorganisms, ${ }^{1-77}$ and as materials in low gap semiconducting electronic devices. ${ }^{78}$ Localization, tumor affinity, and phototoxicity of photosensitizers are known to be determined by vascular permeability and interstitial diffusion, which depend on many factors such as molecular size, configuration, charge, and hydrophilic or lipophilic properties. ${ }^{79}$ Charge determines the anionic, cationic, and neutral character of photosensitizers and is an important factor in the cellular uptake and photodynamic efficacy in photodynamic therapy (PDT).$^{74}$ Electrostatic interactions play important role in binding of photosensitizers to a membrane as the largest difference in the photodynamic activity of cationic and anionic phthalocyanines was observed in a membrane containing negatively charged lipids. It has been found that a water soluble tetrasubstituted cationic aluminum phthalocya nine $(\mathrm{AlPcN}(4))$ revealed efficient binding of this photo sensitizer to phospholipid membranes as compared with 


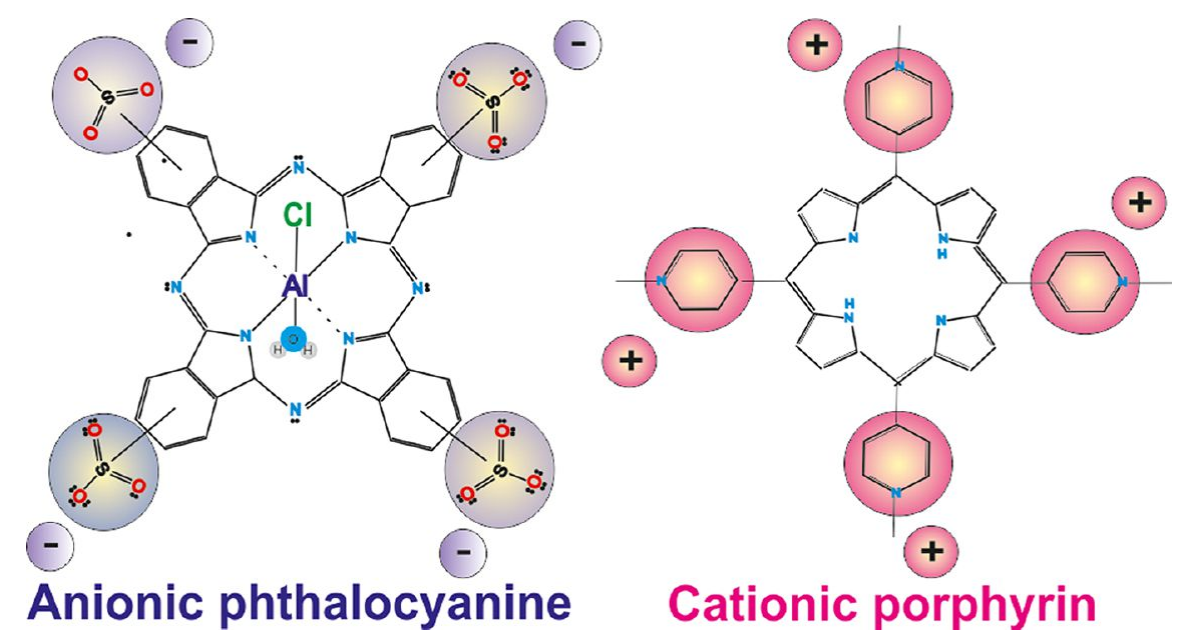

Figure 1. Anionic and cationic photosensitizers.

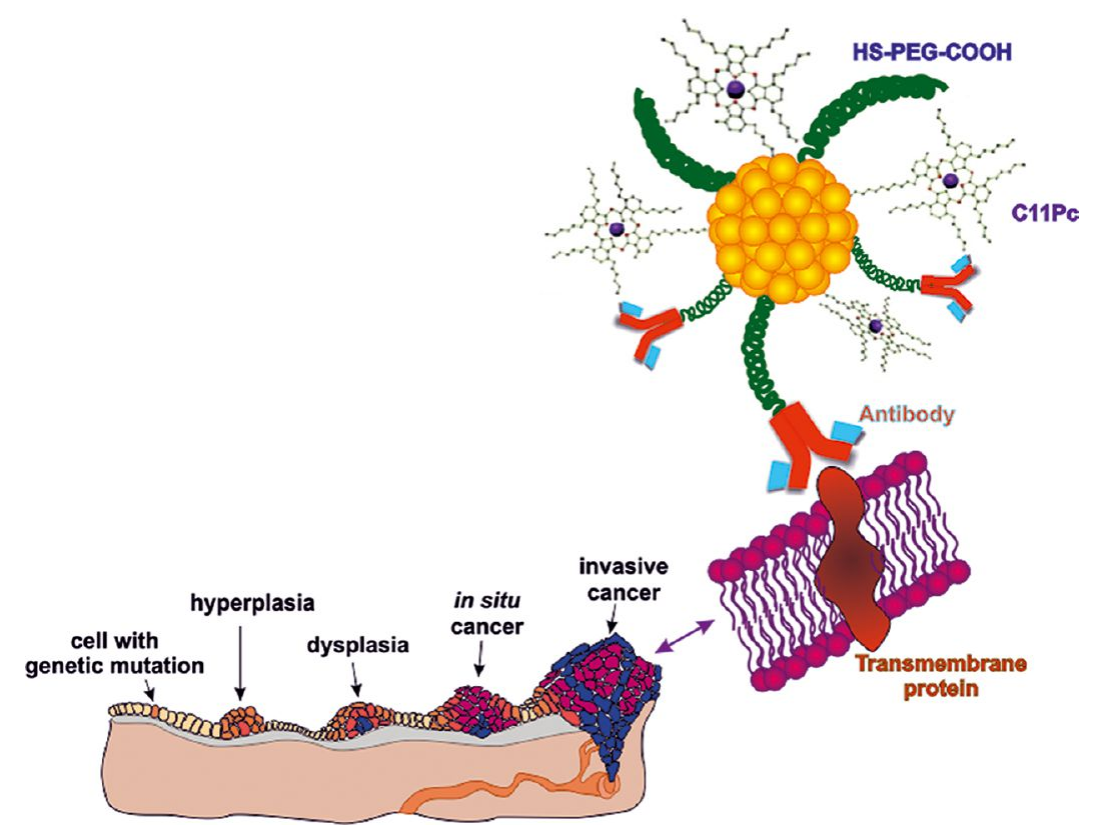

Figure 2. Antibody-phthalocyanine-gold nanoparticle bioconjugate.

anionic tetrasulfonated aluminum and zinc phthalocyanine complexes. ${ }^{75}$ It has been shown that the increase in the degree of sulfonation of phthalocyanine progressively reduced its affinity for the lipid bilayer. ${ }^{75}$ It has been suggested that binding of tetrasulfonated metallophthalocyanines to phospholipid membranes is determined primarily by metal-phosphate coordination. ${ }^{76}$ The hydrophilic or lipophilic property of the photosensitizers is related to their water solubility, which controls aggregation properties, and singlet oxygen production efficiency. Among the hydrophilic photosensitizers, anionic derivatives with sulfo substituents (Figure 1) such as $\mathrm{AlPcS}_{4}$ are one of the best targets for a new generation of photosensitizers. Lipophilic phthalocyanine derivatives are reported to have a higher tumor affinity, but water soluble phthalocyanines are considered to have higher phototoxicity. ${ }^{77,78}$ Initial subcellular localization of each photosensitizer is dependent upon the hydrophobicity and plasma protein binding. Depending on the charge and hydrophilic or lipophilic property the photo sensitizer is localized in various cytoplasmic membranous structures of certain types of cells or their compartments such as a membrane surfaces, endosomal compartments, organelles, and cytoplasm. While anionic phthalocyanines have been reported to have higher selectivity binding than cationic phthalocyanines, some cationic compounds may also target specific sites such as mitochondria. ${ }^{79}$ Mitochondria have been proposed to be one of the most effective subcellular targets for photodamage. $^{79-83}$

Another way to direct the photosensitizer to specific sites of the cell or tissue is to use specific targeting biomolecules ${ }^{84-86}$ (Figure 2) such as conjugated antibodies directed against tumor associated antigens or vascular antigens, such as the ED B domain. ${ }^{87}$

Progress made since the mid 1990s has led to development of photosensitizers that can be localized in the mitochondria, plasma membrane, lysosomes, and nuclei. ${ }^{88,89}$ The specific targeting nanocarriers approach combined with laser spectros copy and Raman imaging has the potential to revolutionize cancer diagnosis and therapy. ${ }^{89}$

In this paper we focus on biological interfaces that the photosensitizer may encounter after suspension and adsorption 
in a biological medium (noncancerous and cancerous human breast tissue) and after interacting with cells components. We will present the dynamics of phthalocyanine at biological interfaces of human breast tissues in the time window ranging from femtosecond to nanoseconds and compare it with the dynamics of the $\mathrm{AlPcS}_{4}$ film on the glass support as well as with the dynamics in aqueous solutions. Characterizing the solidliquid interface is a key challenge in understanding the nanobio interface photochemistry of photosensitizers and energy dissipation in electronic devices. Although we often assume that steady state behavior with the bulk properties of solutions can be translated to the solid phase, this approach must be considerably revised when considering the nano-bio interface. The effects of aggregation on the absorption and emission spectra of metallophthalocyanines in liquid solutions are well documented, ${ }^{44-53}$ but much less information has been accumulated on the solid phases, particularly biological interfaces. Films of phthalocyanines have become relevant in advanced devices like electrochromic displays, optical limiters, light emitting diodes, recordable digital discs, organic con ductors, lasers, nonlinear optical elements, etc. In these applications properties such as conductivity, optical absorbance, and photoconductivity in the solid state phase are impor tant. ${ }^{72,90-93}$ Dynamics of primary events upon light excitation in thin films is even more important than the steady state behavior. There are much less papers reporting on primary events in phthalocyanines occurring on the femtosecond and picosecond scale. ${ }^{1,4,55,68,70,75,76,94-97}$

This paper reports recent progress obtained in our laboratory on understanding light energy collection and dissipation at biological interfaces, with special emphasis on the primary events in light initiated photosensitizers accumulated in cancer ous and noncancerous human breast tissues. Detailed under standing of energy dissipation paths will reveal mechanisms that mediate light induced signal transduction as well as the role of photoreceptors in photostability protection and reparation mechanisms in living cells and tissues. Ultrafast spectroscopies have played an important role in the study of a number of biological processes and provided unique information on primary events and the mechanism of energy. ${ }^{98}$ The experimental methods used in this paper are based on the linear and nonlinear responses such as Raman spectroscopy, Raman imaging, IR, and UV-vis spectroscopies and pumpprobe transient electronic absorption spectroscopy.

In this paper $\mathrm{Al}(\mathrm{III})$ phthalocyanine chloride tetrasulfonic acid $\left(\mathrm{AlPcS}_{4}\right)$ has been chosen (Figure 3) to serve as a model phothosenistizer to study the efficiency of primary processes occurring upon excitation of the chromophore.

We wish to elucidate processes responsible for fast dynamics of $\mathrm{AlPcS}_{4}$ in various microenvironments, particularly at the biological interface of human breast tissue, occurring on the time scale from femtoseconds to nanoseconds monitored by pump-probe transient absorption spectroscopy when excited by femtosecond laser pulses centered at $677 \mathrm{~nm}$, corresponding the absorption maximum of the $\mathrm{Q}$ band of phthalocyanines.

\section{EXPERIMENTAL SECTION}

Phthalocyanine. $\mathrm{Al}(\mathrm{III})$ phthalocyanine chloride tetrasul fonic acid was purchased from Frontier Scientific, Inc. (AlPcS 834). Water was deionized before preparing the solutions.

Steady-State UV-Vis Absorption Measurements. UV-vis absorption electronic spectra were measured with a Varian Cary 5E spectrophotometer in 2 and $0.10 \pm 0.005 \mathrm{~mm}$

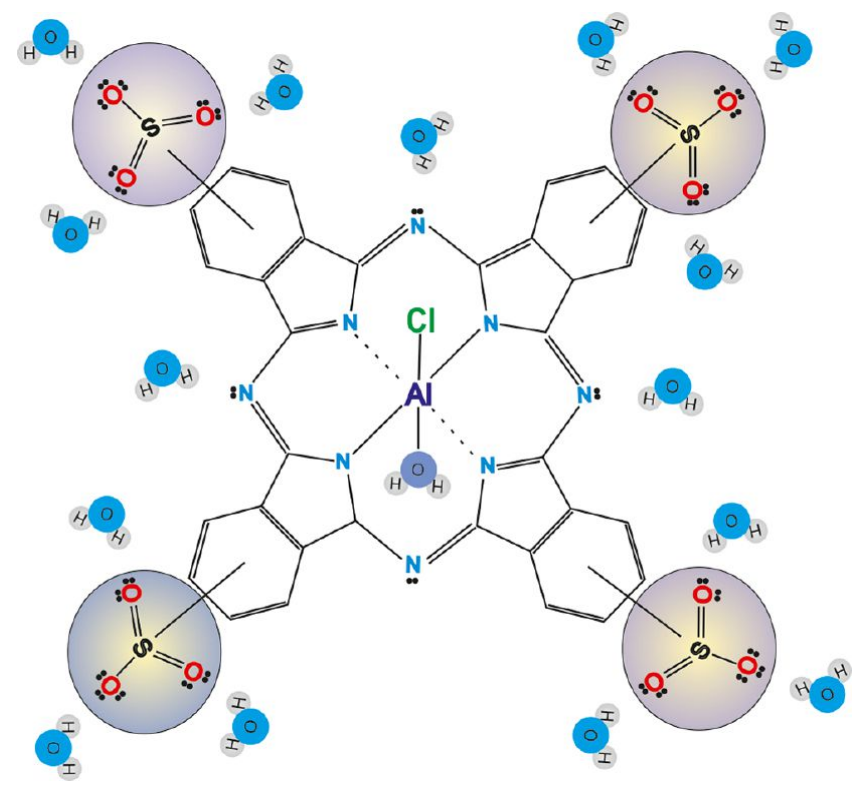

Figure 3. Hydrophilic and anionic character of $\mathrm{AlPcS}_{4}$.

detachable quartz cells (Hellma). Spectra were recorded at 293 $\mathrm{K}$ for aqueous solutions at concentrations of $c=10^{-3} \mathrm{M}$ in the thin sections of $6 \mu \mathrm{m}$ of human breast samples of cancerous and noncancerous tissues stained with $\mathrm{AlPcS}_{4}$.

Pump-Probe Transient Absorption Spectroscopy. The source of femtosecond pulses was a mode locked titanium sapphire femtosecond laser (MIRA, Coherent, $800 \mathrm{~nm}, 76$ $\mathrm{MHz}, 9 \mathrm{~nJ},<200 \mathrm{fs}$ ) pumped with a diode pumped solid state laser (VERDI V5, Coherent, $532 \mathrm{~nm}$ ). The fundamental beam is amplified with a Ti:sapphire regenerative amplifier (Coherent Legend USP, $800 \mathrm{~nm}, 1 \mathrm{kHz}, 3 \mathrm{~mJ}, 50 \mathrm{fs}$ ). The regenerative amplifier is pumped with a diode pumped Nd:YLF laser (JADE, Thales Laser, $527 \mathrm{~nm}, 1 \mathrm{kHz}, 20 \mathrm{~mJ},<200 \mathrm{~ns}$ ). The pulse was split in two and further amplified in a dual single pass amplifier (Coherent Elite Duo, $800 \mathrm{~nm}, 1 \mathrm{kHz}, 2 \times 4.5 \mathrm{~mJ}, 50$ fs). This amplifier is pumped by a high power Nd:YLF laser (Evolution, Coherent, $527 \mathrm{~nm}, 50 \mathrm{~mJ},<200 \mathrm{~ns}$ ). The output of the laser system was split, and two $1 \mathrm{~mJ}$ laser pulses were used to pump two optical parametric amplifiers (OPA, model TOPAS from Light Conversion). These OPA combined by frequency conversion modules generate femtosecond pulses tunable in the 300 and $2600 \mathrm{~nm}$ range. The energy of the pump pulse was adjusted to $2 \mu \mathrm{J}$ in water experiments and $700 \mathrm{~nJ}$ or less in experiments with DMSO. The energy of the probe pulse was at least 100 times lower than the energy of the pump pulse. Pump and probe pulses were overlapped on a $1 \mathrm{~mm}$ optical path of a cell containing the $\mathrm{AlPcS}_{4}$ solution. The solution was circulating in the cell by a magnetic stirrer in order to minimize thermal lensing and photoquenching effects. The time delay between the pump and the probe pulses was adjusted by a motorized translation stage that has a spatial resolution of 1.5 $\mu \mathrm{m}$. Transient absorption signals were measured with two silicon photodiodes (Thorlabs, TDS 1000) placed before and after the sample, which measure the initial $\left(I_{0}\right)$ and transmitted intensity of the probe beam $\left(I_{\mathrm{t}}\right)$, respectively. $I_{0}$ was normalized with respect to the intensity of the pump beam, which was measured with the same type of photodiode. The absorption signal $S(t)$ was calculated as $\log \left(I_{0} / I_{\mathrm{t}}\right)$. The transient absorption signal $\Delta A(t)$ was computed by subtracting the absorption signal measured with and without the pump pulse. For that reason the 
pump beam was chopped at $40 \mathrm{~Hz}$. The typical measurement error of $\Delta A$ was better than $10^{-3}$.

Patients and Samples. All procedures were conducted under a protocol approved by the institutional Bioethical Committee at the Medical University of Lodz, Poland (RNN/ 29/11/KE, RNN/30/11/KE, RNN/31/11/KE). We studied ductal and lobular carcinoma (in situ and infiltrating) as well as various benign changes including benign dysplastic and neoplastic lesions. The total number of patients was 222 . Raman spectroscopy and Raman imaging have been employed to analyze breast cancer specimens. Breast tissue samples were taken during a surgical operation. The research did not affect the course of the operation or treatment of the patients.

In order to visualize and identify tissue structures by Raman imaging and IR spectroscopy we developed the method of processing surgical specimen. First, we checked the effect of standard steps used in histology protocols on the Raman measurements, such as formalin fixation, paraffin embedding, and coating to adhere a cover glass to a microscope slide. We found that using the standard chemical fixative to preserve tissue from degradation-10\% neutral buffered formalin (4\% formaldehyde in phosphate buffered saline) does not introduce changes in the Raman spectra. This conclusion is based on comparison between the results obtained for fresh tissue samples (167 patients) and those for formalin-fixed tissues (55 patients). In contrast, paraffin embedding is not the appropriate protocol for both Raman and IR measurements. The paraffinization protocol contains a few steps: dehydration with alcohols, clearing with xylene, infiltrating with the embedding material of paraffin vax, and embedding tissues into paraffin blocks, which may introduce artifacts in Raman spectra resulting from tissue processing. We found that the frozen section procedure, where the frozen fresh tissue (or formalin fixed tissue) is sliced using a microtome (Microm HM 550 , Sermed) into $2-6 \mu \mathrm{m}$ thick sections, is the most appropriate protocol for Raman and IR measurements. Fresh tissue obtained from surgery is snapped in liquid nitrogen. Frozen fresh tissue blocks are stored at $-80{ }^{\circ} \mathrm{C}$ until needed for processing. In most cases they are used within a few hours from preparation. A process similar to bread loafing has been employed to cut the surgical specimens into 4 or more sections from the tumor mass and from the safety margins of the excised tumor where no carcinoma was detected by the histopathol ogists. Frozen tissue is cut into thin sections at $-25{ }^{\circ} \mathrm{C}$ for unfixed tissue and $-17{ }^{\circ} \mathrm{C}$ for fixed tissue. This procedure ensures that the very thin, adjacent sections represent the same breast structures and the same type of pathology. Thin slices without staining are mounted on a glass slide for Raman measurements and on $\mathrm{BaF}_{2}$ windows for IR and UV-vis measurements. For both IR and Raman measurements the tissue specimen is not covered with another layer of glass attached to the sample, because a specific adhesive introduces artifacts due to vibrational spectra of the adhesive in the same spectral range.

The adjacent sections of tissue are mounted on glass slides, stained with hematoxylin and eosin, and covered with another layer of glass with a specific adhesive (Histokitt, Glaswar enfabrik Karl Hecht GmbH \& Co KG, CAS no. 1330 20 7) for histology examination. After Raman measurements the slices are stained and examined by pathologists. As the quality of the slides produced by the frozen section is lower for purposes of histology examination than formalin fixed, wax embedded tissue processing, the standard histology processing is addi tionally performed for a more accurate diagnosis for each patient. Histological analysis was performed according to standard histology protocols by professional medical doctors, board certified as pathologists, from the Medical University of Lodz, Department of Pathology, Chair of Oncology.

Raman Spectroscopy and Imaging. All Raman images and spectra reported in this paper were acquired using a Raman spectrometer Ramanor U1000 (Jobin Yvon, JY) excited with the ion Ar laser $(514 \mathrm{~nm}$ ) and alpha 500 RA (WITec, Ulm, Germany) model consisting of an Olympus microscope, coupled with an UHTS spectrometer and a Newton CCD camera operating in standard mode with $1024 \times 127$ pixels, at $-64{ }^{\circ} \mathrm{C}$ with full vertical binning. The laser beam doubled SHG of the Nd:YAG laser $(532 \mathrm{~nm})$ is focused on the sample with a numerical aperture, NA, of 0.50 to the spot of $200 \mathrm{~nm}$. The average laser excitation power was $10 \mathrm{~mW}$.

The 2D array images of tens of thousands of individual Raman spectra were evaluated by the basis analysis method. In this data analysis method each measured spectrum of the $2 \mathrm{D}$ spectral array is compared to basis spectra using a least squares fit. Such basis spectra are created from the average spectra from three different areas in the sample. The weight factor in each point is represented as a $2 \mathrm{D}$ image of the corresponding color and mixed coloring component.

Infrared Spectroscopy. IR spectra were recorded using Specord M 80, Germany. Specord M80 is a double beam spectrometer recording in the range from 4000 to $200 \mathrm{~cm}^{-1}$ $(2.5-50 \mu \mathrm{m})$ with accuracy changing of from \pm 0.8 to $\pm 0.3 \mathrm{~cm}$ ${ }^{-1}$ depending on the spectral range. Spectra were scanned with a step of $4 \mathrm{~cm}^{-1}$ and recorded in the range $800-4000 \mathrm{~cm}^{-1}$ at $293 \mathrm{~K}$.

\section{RESULTS}

In this section we present the results for $\mathrm{AlPcS}_{4}$ at the interface of the noncancerous and cancerous human breast tissues by Raman, IR, and UV-vis steady state spectroscopies as well as time resolved transient electronic absorption by pump-probe spectroscopy.

In order to identify human breast structures and the corresponding biochemical constituents that produce the vibrational patterns of behavior, we recorded the histological images and Raman and IR spectra for human breast tissues of the same patient P91. Histopathological images of breast tissue from the safety margin of the tumor mass (normal, non cancerous) and from the tumor mass (cancerous) are presented in Figure 4.

One can see that normal breast tissue consists mainly of fatty tissue with embedded ducts and blood vessels (Figure 4a). Fatty tissue is hydrophobic as it is formed of glycerol monooleate (GMO). ${ }^{99}$ Cancerous tissue is dominated by epithelial cells, which produce milk and are lined with the ducts
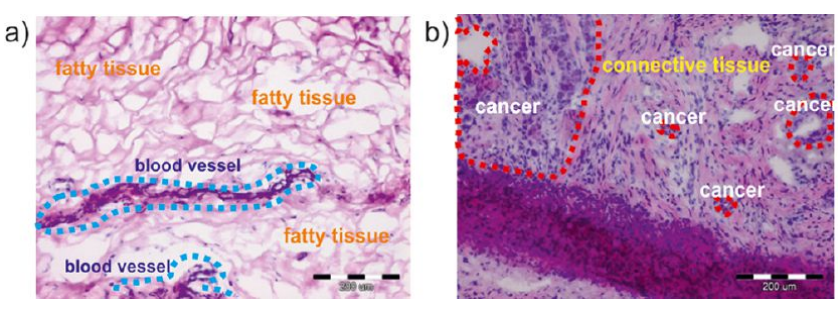

Figure 4. Histological images of the noncancerous (a) and cancerous (infiltrating ductal carcinoma) (b) human breast tissue of patient P91. 

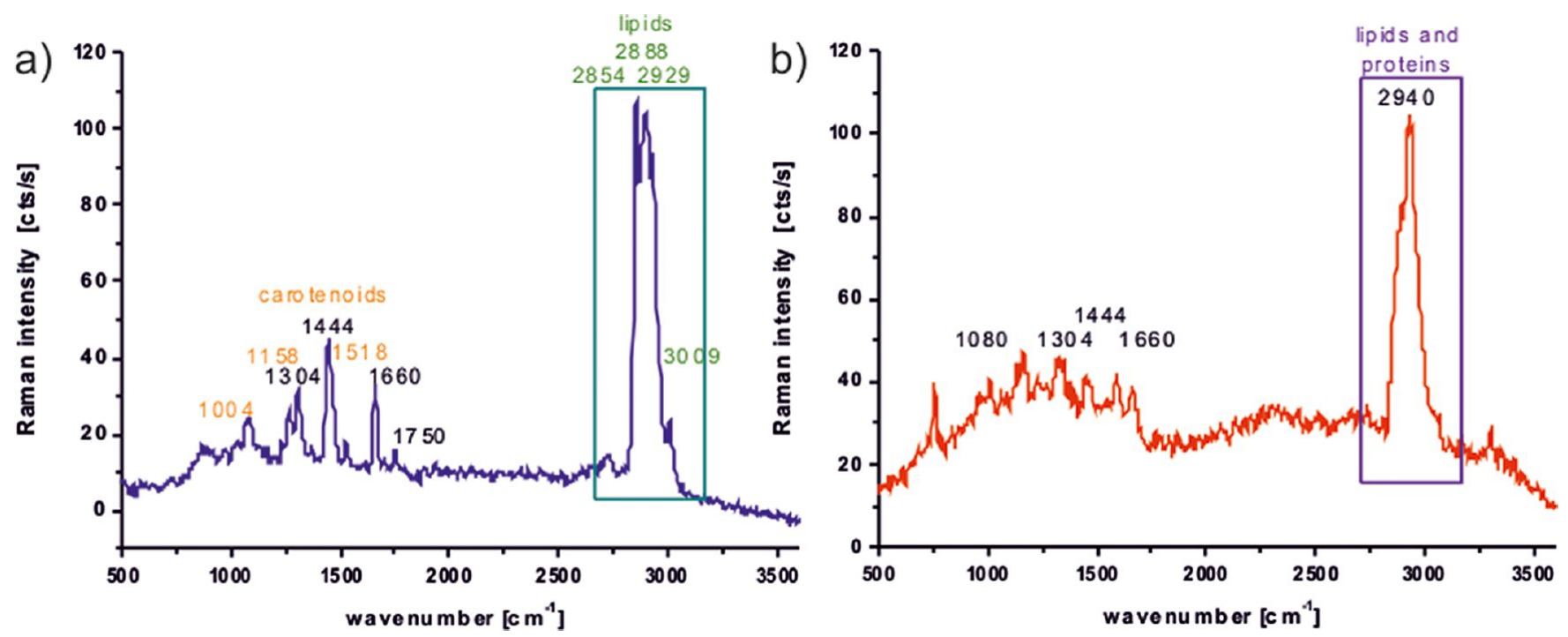

Figure 5. Average Raman spectra of noncancerous (a) and cancerous (b) breast tissue of patient P91.

of the breast. Epithelial cells are the origin of $80 \%$ of all breast tumors. They contain no blood vessels, so nourishment is provided via diffusion of substances from the connective tissue (Figure $4 \mathrm{~b}$ ). The surface of the cancerous tissue is hydro philic, ${ }^{100}$ and the level of various proteins is markedly elevated during disease development.

Steady-State Raman Scattering. Figure 5 shows the Raman spectra of typical noncancerous and cancerous human breast tissue of patient P91 of a total number of 222 patients.

The first observation that one makes when confronting the results are noticeable differences between the Raman spectra of noncancerous breast tissue surrounding the tumor from the safety margin (Figure 5a) and those of cancerous breast tissue from the tumor mass (Figure 5b). First, comparison between the Raman spectra demonstrates that noncancerous tissue contains Raman peaks characteristic for glycerol monooleate derivatives, ${ }^{101-105}$ which are not observed in the Raman spectra of cancerous tissue. Second, detailed inspection of Figure 5 demonstrates that the strongest signals in the Raman spectrum of noncancerous tissue originate from carotenoids at 1158 and $1518 \mathrm{~cm}^{-1}$, which are not visible in the Raman spectrum of cancerous tissue. It clearly indicates that noncancerous breast tissue contains a significant contribution of glycerol monooleate derivatives originating from the adipose tissue that acts as a dynamic reservoir for carotenoids filling the spaces around the lobules and ducts and fatty acids that make up the cell membrane and nuclear membrane. In contrast, cancerous breast tissue does not contain any carotenoids.

Third, a marked distinction can be observed in the lipidprotein profiles in the region of $2800-3000 \mathrm{~cm}^{-1}$, where the contribution from the monounsaturated fatty acids that are common constituents of triglycerides of the adipose tissue dominate the Raman spectrum of noncancerous tissue in contrast to the Raman spectra of cancerous tissue. We have shown ${ }^{101-105}$ that the Raman spectra demonstrate a mixed lipid-protein profile. This finding corresponds to the fact that in contrast to normal cells abnormal cells divide in an uncontrolled process of cell growth that synthesizes large amounts of proteins.

Steady-State IR Absorption. To obtain complementary information on vibrational features of noncancerous and cancerous tissues it would be very interesting to compare the
Raman spectra with the IR spectra. Figure 6 shows typical IR spectra for noncancerous and cancerous breast tissue of the

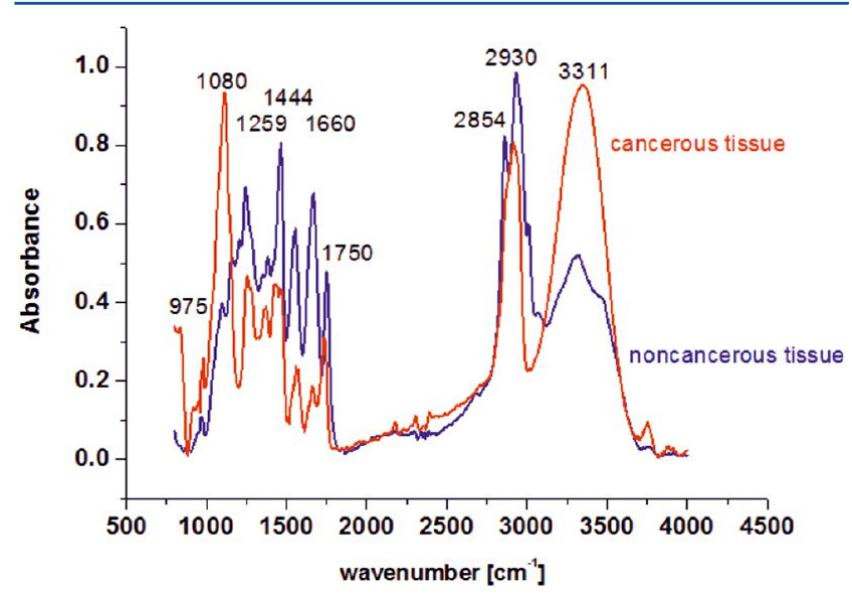

Figure 6. Comparison between the IR spectra of noncancerous and cancerous (infiltrating ductal carcinoma) breast tissue of patient P91.

same patient (P91) as in Figures 4 and 5. In contrast to the results presented in Figure 5, where Raman spectra of noncancerous and cancerous tissues differ significantly, the IR spectra in Figure 6 are almost identical, although the absorbance of various vibrations differs markedly.

Steady-State Absorption Measurements. Steady state absorption spectra of $\mathrm{AlPcS}_{4}$ in water solution, in film on the glass support, and in films at the biological interface of noncancerous and cancerous human breast tissues are shown in Figure 7.

The Soret band and Q band are observed at 340 and $678 \mathrm{~nm}$, respectively. The $\mathrm{Q}$ band $\left(\mathrm{S}_{0} \rightarrow \mathrm{S}_{1},\left(\mathrm{a}_{2 \mathrm{u}}\right) \rightarrow\left(\mathrm{e}_{\mathrm{g}}\right)\right.$ transition $)$ in solution has a sharp maximum at $678 \mathrm{~nm}$ as well as weaker bands in the blue side with maxima at 643 and $607 \mathrm{~nm}$. We have shown that the absorption bands are very similar in the concentration range of $10^{-5}-10^{-3} \mathrm{M}$, indicating that $\mathrm{AlPcS}_{4}$ is dominated by a monomeric form in aqueous solution. ${ }^{1}$ Assuming the thickness of the AlPc $S_{4}$ layer as $100 \mu \mathrm{m}$ and the absorption coefficient the same as in solution we estimated 


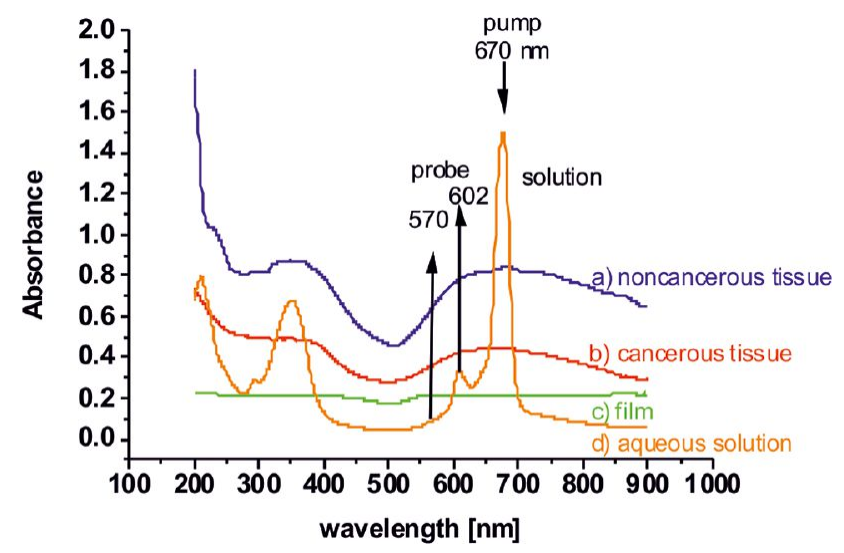

Figure 7. Absorption spectra of $\mathrm{AlPcS}_{4}$ in noncancerous tissue (a), cancerous tissue (b), film (c), and aqueous solution $c=10^{-3} \mathrm{M}$ (d).

the concentration of the photosensitizer in tissues as equal to $10^{-2} \mathrm{M}$.

At such a high concentration we cannot neglect effects related to aggregation of $\mathrm{AlPcS}_{4}$. One can see from Figure 7 that in contrast to solutions, absorption spectra at the biological interface of the tissues and in the film of pure $\mathrm{AlPcS}_{4}$ on the glass substrate are represented by broad, structureless bands in the region corresponding to absorption of monomers, dimers, and aggregates of higher order. Optical and spectroscopic properties of dimeric forms of phthalocyanines have been reviewed by Tran Thi. ${ }^{106}$

Excited-State Dynamics of $\mathrm{AIPcS}_{4}$ at Biological Interfaces of Human Breast Tissue and Film and in Aqueous Solutions. Dimerization of phthalocyanines affects effectively ultrafast dynamics of these classes of compounds. It has been show that excited state lifetimes of phthalocyanines homodimers are short, and in some cases, ligand to ligand charge transfer seems to be an effective deactivation pathway. Nikolaitchik et al. have shown that according to exciton theory in face to face dimer transitions between the ground state and the lower exciton state are symmetry forbidden, and the lack of fluorescence in such systems indicates that the upper exciton state rapidly converts to the lower one, which undergoes subsequent nonradiative relaxation, including intersystem crossing. ${ }^{107}$ The absence of fluorescence in cofacial dimers was related also to the decrease of the triples quantum yields and shortening of triplet state lifetimes and dramatic increase of internal conversion rates by a factor of 20-300. The enhancement of internal conversion rates may be related to the fact that exciton splitting places the lower exciton state closer to the ground state. The increased intersystem crossing rate may also be a manifestation of the lowering of the energy gap with the lower exciton state closer to the corresponding triplet state. ${ }^{107}$ Similar observations have been made by Ma et al. for iron phthalocyanine. ${ }^{108}$ They have shown that in condensed phases effective intermolecular interactions and molecular distortion result in a shortening of the excited state lifetime and a very high intersystem crossing rate. The influence of aggregation on femtosecond excited state dynamics has been investigated also by Peyghambarian et al. ${ }^{109}$ They have shown that the induced absorption signal develops as the absorption bleaching signal decays, suggesting exciton decay into a subgap state. ${ }^{109}$ Fluorescent phthalocyanine dimers have been investigated by Speirs et al. ${ }^{110}$ They have shown that the fluorescence is typical for dimers deviating from an eclipsed cofacial structure.

In order to study energy dissipation and dynamical alterations in the phthalocyanine structure, a system was triggered with a laser and monitored with a time resolution of $50 \mathrm{fs}$. To obtain insight into mechanisms of energy dissipation we monitored the dynamics of $\mathrm{AlPcS}_{4}$ in the interfacial region of human breast tissues upon excitation at $677 \mathrm{~nm}$, which promotes the $S_{0} \rightarrow S_{1}$ transition, with the main contribution from the $\left(\mathrm{a}_{2 \mathrm{u}}\right) \rightarrow\left(\mathrm{e}_{\mathrm{g}}\right)$, in the $\mathrm{Q}$ band. Upon excitation the molecules were probed with different time delays at different wavelengths $(570,602$, and $670 \mathrm{~nm})$.

Figure 8 shows the transient absorption signals $\Delta A(t)$ of $\mathrm{AlPcS}_{4}$ at the interface of cancerous and noncancerous tissues and in the film at the glass support as a function of the time delay in the pump-probe experiments when pumped with 677 $\mathrm{nm}$ and probed with $664 \mathrm{~nm}$. The results are presented in the full time window up to $1 \mathrm{~ns}$ (Figure $8 \mathrm{a}$ ) and in the narrow window up to $10 \mathrm{ps}$ (Figure $8 \mathrm{~b}$ ).

Figure 8 shows that directly upon excitation with the laser pump pulse at $677 \mathrm{~nm}$ a negative signal at $670 \mathrm{~nm}$ has been recorded. The negative signal has been assigned to bleaching of the ground state $S_{0}$ due to the $S_{0} \rightarrow S_{1}$ transition in the Q band. The bleach is instantaneous and limited by the laser pulse width. Recovery of the bleach at $670 \mathrm{~nm}$ is found to be three exponential and fitted with time constants of $130 \pm 0.10 \mathrm{fs}$, $1.53 \pm 0.19 \mathrm{ps}$, and $37.86 \pm 5.25$ ps for cancerous tissue and $110 \pm 0.10 \mathrm{fs}, 1.34 \pm 0.16 \mathrm{ps}$, and $40.72 \pm 7.86 \mathrm{ps}$ for noncancerous tissue. Recovery of the bleach in the $\mathrm{AlPcS}_{4}$ film is found to be also three exponential with time constants $830 \pm$ $100 \mathrm{fs}, 7.31 \pm 1.02 \mathrm{ps}$, and $56.03 \pm 6.58$ ps. This indicates that
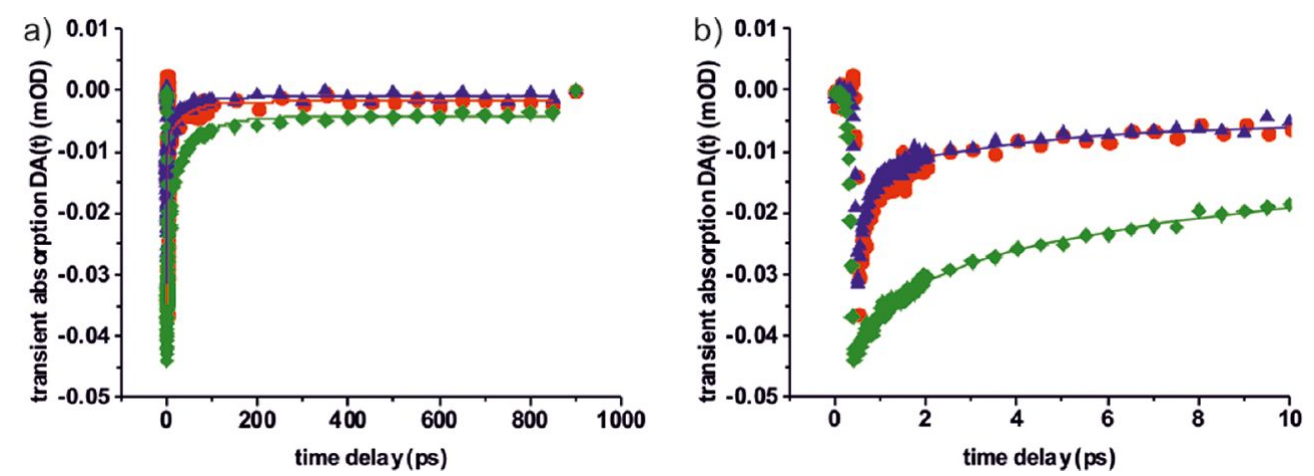

Figure 8. Transient absorption signal $\Delta A(t)$ of $\operatorname{AlPcS}_{4}$ in noncancerous $(\bullet)$ and cancerous $(\boldsymbol{\Delta})$ human breast tissues and in film $(\boldsymbol{})$ as a function time delay in the full time window up to $1 \mathrm{~ns}$ (a) and $10 \mathrm{ps}$ (b), pumped at $677 \mathrm{~nm}$ and probed at $670 \mathrm{~nm}$. 

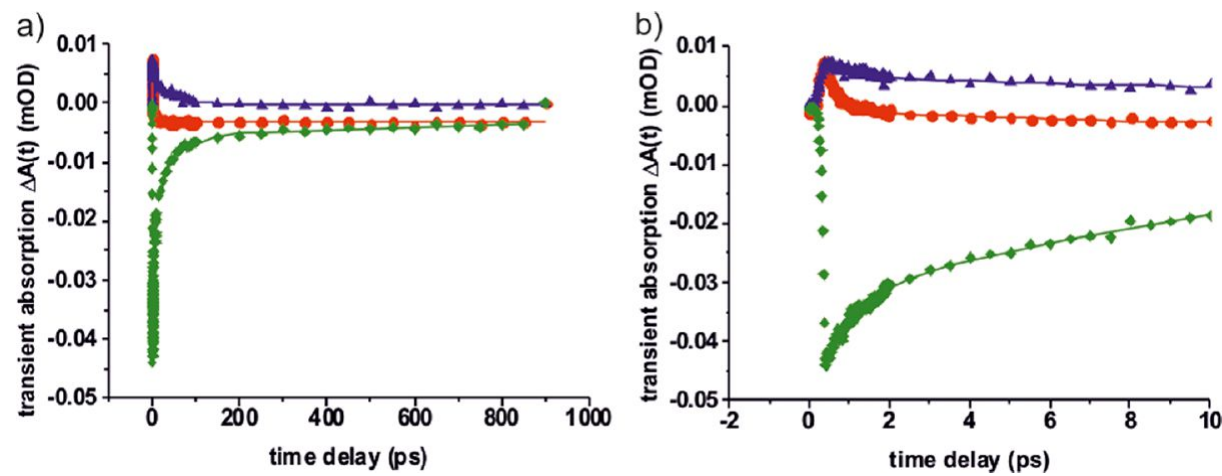

Figure 9. Transient absorption signal $\Delta A(t)$ of $\operatorname{AlPcS}_{4}$ in noncancerous $(\boldsymbol{\bullet})$ and cancerous $(\boldsymbol{\Delta})$ human breast tissues and film $(\boldsymbol{\nabla})$ as a function time delay in the full time window up to $1 \mathrm{~ns}$ (a) and $10 \mathrm{ps}(\mathrm{b})$, pumped at $677 \mathrm{~nm}$ and probed at $602 \mathrm{~nm}$.

the dynamics recovery of the ground state $S_{0}$ for noncancerous and cancerous tissues is similar. In contrast, all time constants are shorter than those characterizing the $\mathrm{AlPcS}_{4}$ film dominated by aggregation effects, which indicates that the dynamics of the photosensitizer is sensitive to the specific microenvironment of the biological tissue.

Figure 9 shows that the instantaneous bleach of the negative signal of $\mathrm{AlPcS}_{4}$ in water at $670 \mathrm{~nm}$ is accompanied by a sudden rise at $602 \mathrm{~nm}$ that is followed by decay.

The positive signal has been assigned to the excited state absorption (ESA) of the excited state $S_{1}$ generated by the $S_{0} \rightarrow$ $S_{1}$ transition in the $\mathrm{Q}$ band. The results clearly demonstrate that the dynamics of $\mathrm{AlPcS}_{4}$ in noncancerous tissue is markedly faster than that in cancerous tissue. These decays are found to be three exponential and fitted with time constants of $810 \pm 40$ fs, $5.63 \pm 5.49$ ps, and $59.90 \pm 12.85$ ps for cancerous tissue and $176 \pm 20 \mathrm{fs}, 847 \pm 422 \mathrm{fs}$, and $6.03 \pm 1.92 \mathrm{ps}$ for noncancerous tissue. In the contrast to biological interfaces, the film of $\mathrm{AlPcS}_{4}$ exhibits a negative bleaching signal with recovery described by the three exponential with time constants $163 \pm$ $25 \mathrm{fs}, 1.56 \pm 0.42 \mathrm{ps}$, and $21.59 \pm 4.14 \mathrm{ps}$.

\section{DISCUSSION}

In order to elucidate further electronic dynamics features that can be rationalized from signals of the transient absorption $\Delta A(t)$ presented in the previous section, we need to understand the details of the electronic transitions in phthalocyanines that are induced and probed by the laser pulses in the pump-probe experiments. Molecular orbitals of selected phthalocyanines are known according to calculations from the literature. ${ }^{1,45,64-66}$ Figure 10 shows Kohn-Sham orbitals from our TD DFT calculations. ${ }^{1}$

Figure 11 shows the comparison of the transient absorption signal $\Delta A(t)$ of $\mathrm{AlPcS}_{4}$ as a function time delay in noncancerous and cancerous human breast tissues, in the film, and in aqueous solution.

Recovery of the bleach of $\mathrm{AlPcS}_{4}$ in solution at $670 \mathrm{~nm}$ was fitted as a two exponential function with time constants of 5.09 \pm 0.99 and $203.16 \pm 18.75 \mathrm{ps}^{1}$ and as a three exponential function with $4.27 \pm 1.68,47.21 \pm 124.44$, and $232.52 \pm 81.00$ ps. Fitting data in the early time window extending to 2 ps found that initial recovery of the signal of $\mathrm{AlPcS}_{4}$ in water solution at $570 \mathrm{~nm}$ is monoexponential and can be fitted with a time constant of $405 \pm 164$ fs in water. ${ }^{1}$ The time constants in solution are on the same order as those obtained by Howe et al. ${ }^{55}$ for $\mathrm{PcS}_{4}$ and $\mathrm{ZnPcS}_{4}$ in $\mathrm{DMSO}$ probed at 720, 790, and $820 \mathrm{~nm}$.

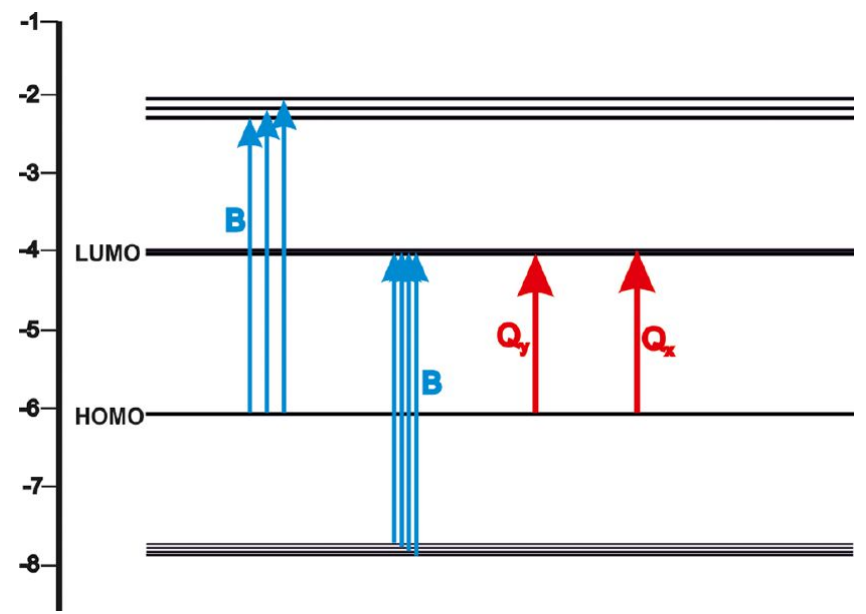

Figure 10. Energy level diagrams of the aluminum complex of tetrasulfonated $\mathrm{AlPcS}_{4}$; TD DFT calculations in ref 1 .

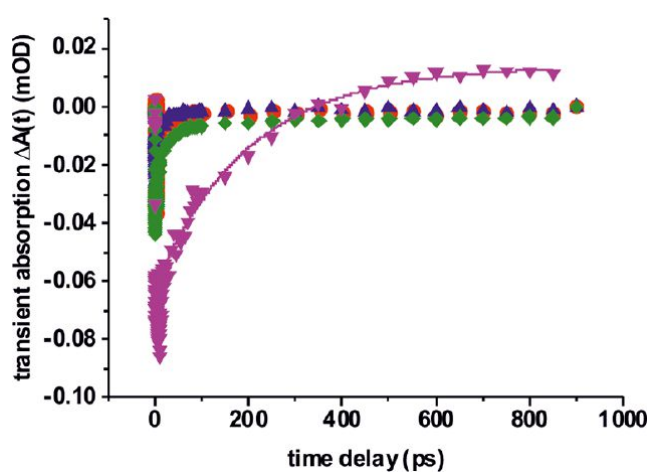

Figure 11. Comparison of the transient absorption signal $\Delta A(t)$ of $\mathrm{AlPcS}_{4}$ as a function time delay in noncancerous (-) (a) and cancerous $(\mathbf{\Delta})$ (b) human breast tissues, film ( ) (c) (pumped at 677 $\mathrm{nm}$ and probed at $670 \mathrm{~nm}$ ), and aqueous solution $(\boldsymbol{\nabla})$ (concentration $10^{-3} \mathrm{M}$, pumped at $677 \mathrm{~nm}$, probed at $664 \mathrm{~nm}$ ).

The picture that emerges from the results presented so far provides a basis for a substantial revision of the commonly accepted assumption that the photochemistry of the bulk properties of photosensitizers in solutions can be translated to the interfacial region. This approach must be considerably revised when considering the nano-bio interface of biological tissue. The first observation that one makes when confronting the results from the comparison in Figure 11 are noticeable differences between the dynamics of the photosensitizer in 
Table 1. Comparison of Time Constants of $\mathrm{AlPcS}_{4}$ at Biological Interfaces for Noncancerous and Cancerous Tissues, Film (pump $677 \mathrm{~nm}$, probe $670 \mathrm{~nm}$ ), and Solution (pump $678 \mathrm{~nm}$, probe $660 \mathrm{~nm}$ )

\begin{tabular}{|c|c|c|c|c|c|}
\hline \multirow[b]{2}{*}{ noncancerous tissue } & \multicolumn{5}{|c|}{ time constants } \\
\hline & $110 \pm 10 \mathrm{fs}$ & & $1.34 \pm 0.16 \mathrm{ps}$ & $40.72 \pm 7.86 \mathrm{ps}$ & \\
\hline cancerous tissue & $130 \pm 0.1 \mathrm{fs}$ & & $1.53 \pm 0.19 \mathrm{ps}$ & $37.86 \pm 5.25 \mathrm{ps}$ & \\
\hline film & & $830 \pm 100 \mathrm{fs}$ & $7.31 \pm 1.02 \mathrm{ps}$ & $56.03 \pm 6.58 \mathrm{ps}$ & \\
\hline solution $^{1}$ & & & $4.27 \pm 1.68 \mathrm{ps}$ & $47.21 \pm 124.44 \mathrm{ps}$ & $232.52 \pm 81.00 \mathrm{ps}$ \\
\hline
\end{tabular}

solution and that at interfacial regions of the biological tissue. Indeed, the dynamics of $\mathrm{AlPcS}_{4}$ in solution is much slower than that at the biological interfaces of the tissues and in the film, for which we find no evidence of the slow component (232.52 \pm $81.00 \mathrm{ps}$ ). This observation confirms that aggregation in the solid phases results in shortening of the relaxation times.

Table 1 compares the time constants characterizing the dynamics of the ground state recovery of $\mathrm{AlPcS}_{4}$ at biological interfaces for noncancerous and cancerous tissues, in film, and in aqueous solution. One can see that that the dynamics recovery of the ground state $S_{0}$ for noncancerous and cancerous tissues is similar, in contrast to the dynamics of $\mathrm{AlPcS}_{4}$ in solution, which is much slower.

A similar picture emerges from comparison between the dynamics at biological interfaces and those in solution for the positive ESA signal decay at $602 \mathrm{~nm}$. Figure 12 shows the comparison of the transient absorption signals $\Delta A(t)$ of $\mathrm{AlPcS}_{4}$ as a function of time delay.

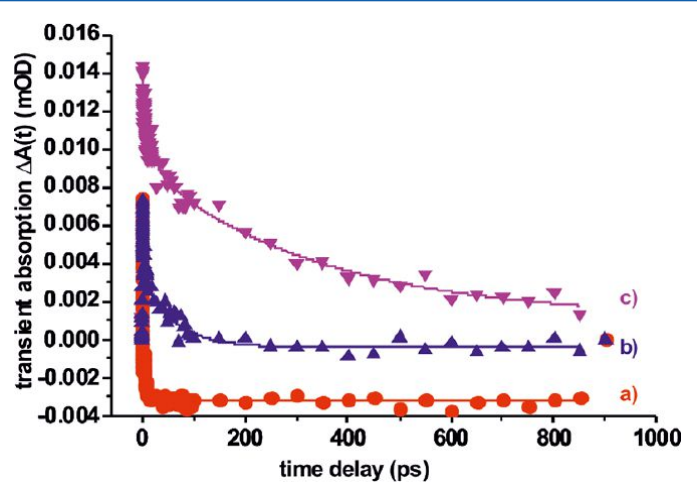

Figure 12. Comparison of the transient absorption signal $\Delta A(t)$ of $\mathrm{AlPcS}_{4}$ as a function of time delay in noncancerous (a) (a) and cancerous (A) (b) human breast tissues (pumped at $677 \mathrm{~nm}$ and probed at $602 \mathrm{~nm}$ ), and aqueous solution $(\boldsymbol{\nabla})(\mathrm{c})$ (concentration $10^{-3}$ $\mathrm{M}$, pumped at $677 \mathrm{~nm}$, probed at $570 \mathrm{~nm}$ ).

The comparison between Figure $12 \mathrm{a}$ and $12 \mathrm{~b}$ and Figure $12 \mathrm{c}$ demonstrates that the decay of the ESA signal in $\mathrm{AlPcS}_{4}$ at biological interfaces is markedly faster than that in solution. The decay in solution is found to be much slower than that observed at biological interfaces of the tissues and in the film. This observation confirms once again that aggregation in the solid phases results in shortening of the relaxation times.
The decay in solution has been fitted as the three exponential function with time constants of $2.37 \pm 0.71,28.07 \pm 24.18$, and $345.81 \pm 107.87$ ps. Fitting data in the early time window extending to $10 \mathrm{ps}$ found that the initial decay of the signal at $570 \mathrm{~nm}$ is monoexponential and can be fitted with a time constant of $560 \pm 94 \mathrm{fs}$ in water.

Table 2 compares the time constants characterizing the dynamics of the excited state $\mathrm{S}_{1}$ decay of $\mathrm{AlPcS}_{4}$ at biological interfaces for noncancerous and cancerous tissues, in film, and in aqueous solution.

One can see that that the dynamics of the excited state $S_{1}$ decay for noncancerous tissue is much faster than that of cancerous tissues. The dynamics of the noncancerous tissue is described by three time constants $(176 \pm 20 \mathrm{fs}, 847 \pm 422 \mathrm{fs}$, $6.03 \pm 1.92 \mathrm{ps})$ and does not contain slow components that are observed in cancerous tissue $(59.90 \pm 12.85 \mathrm{ps})$, in film (21.59 $\pm 4.14 \mathrm{ps})$, and in solution $(28.07 \pm 24.18$ and $345.81 \pm$ $107.87 \mathrm{ps})$.

The picture that emerges from the results presented in the paper is as follows. The dynamics of $\mathrm{AlPcS}_{4}$ in the excited state at biological interfaces reveals three different time scales: (a) a very fast component of a hundred femtoseconds, (b) a few picoseconds, and (c) 20-60 ps, in contrast to the dynamics in solutions that exhibits an additional component in the range of a few hundred picoseconds. The fast femtosecond component has been also reported in the literature. ${ }^{1,68,70,111}$ Savolainen et al. $^{68}$ assigned the shortest time constant to inertial response of solvation. Fournier et al. ${ }^{111}$ assigned a constant of $<210 \mathrm{fs}$ observed in NiPc and $\mathrm{CuPc}$ to the lifetime $\mathrm{S}_{2} \rightarrow \mathrm{S}_{1}$ internal conversion. Rao et al. ${ }^{70}$ assigned the time constant $<170$ fs to phase relaxation of $S_{n}$ states. Our results on the $\mathrm{AlPcS}_{4}$ dynamics in aqueous and organic solutions ${ }^{1}$ demonstrate that the fast femtosecond component is not sensitive to the solvation dynamics as the time constants are almost identical in various solvents. Thus, we find it unlikely that it is assigned to inertial response of solvation. We assigned the femtosecond component of the ESA signal for $\mathrm{AlpcS}_{4}$ in solution to vibrational wavepacket dynamics of higher electronic states of $\mathrm{AlPcS}_{4}$ immediately upon excitation. ${ }^{1}$ However, detailed inspection into the results presented in Tables 1 and 2 demonstrates that the dynamics in confined environments at the biological interface of the tissue is markedly different from that observed in solutions. The ultrafast femtosecond component in biological tissue is clearly visible both in the

Table 2. Comparison of Time Constants of $\mathrm{AlPcS}_{4}$ at Biological Interfaces Od the Noncancerous and Cancerous Tissues, Film (pump $677 \mathrm{~nm}$, probe $602 \mathrm{~nm}$ ), and Solution (pump $678 \mathrm{~nm}$, probe $571 \mathrm{~nm}$ )

\begin{tabular}{llllll} 
& \multicolumn{5}{c}{ time constants } \\
\cline { 2 - 6 } noncancerous tissue & $176 \pm 20 \mathrm{fs}$ & $847 \pm 422 \mathrm{fs}$ & $6.03 \pm 1.92 \mathrm{ps}$ & \\
cancerous tissue & & $810 \pm 40 \mathrm{fs}$ & $5.63 \pm 5.49 \mathrm{ps}$ & $59.90 \pm 12.85 \mathrm{ps}$ \\
film & $163 \pm 25 \mathrm{fs}$ & $1.56 \pm 0.42 \mathrm{ps}$ & $21.59 \pm 4.14 \mathrm{ps}$ & \\
solution $^{1}$ & $560 \pm 94 \mathrm{fs}$ & $2.37 \pm 0.71 \mathrm{ps}$ & $28.07 \pm 24.18 \mathrm{ps}$ & $345.81 \pm 107.87 \mathrm{ps}$
\end{tabular}


dynamics of the excited state $S_{1}$ probed at $602 \mathrm{~nm}$ and in the ground state $S_{0}$ recovery probed at $670 \mathrm{~nm}$. It indicates that the interpretation of the ultrafast component as originating only from the vibrational wavepacket dynamics of the higher electronic states of $\mathrm{AlPcS}_{4}$ immediately upon excitation used for the solution ${ }^{1}$ cannot be directly translated to the confined and solid phases of biological interfaces. Taking into account that we find no evidence of the slow component in energy dissipation of $\mathrm{AlPcS}_{4}$ in noncancerous tissue that was reported for many phthalocyanines in solution (232 ps, ${ }^{1} 2.9 \mathrm{~ns},{ }^{68}$ Howe $^{55}$ ), it is possible that the ultrafast component of $110 \mathrm{fs}$ recorded in the dynamics of the ground state $S_{0}$ (Table 1 ) in noncancerous tissue is related to the specific channel of energy dissipation via radiationless decay at a conical intersection. ${ }^{111}$ In contrast, in cancerous tissue the ultrafast component is not recorded in the dynamics of excited state $S_{1}$ (Table 2). It is obviously that the time constant of $810 \mathrm{fs}$, which is markedly larger, must reflect a different pathway of energy dissipation of $\mathrm{AlPcS}_{4}$ in cancerous tissue. It is well known that the phthalocyanine based photosensitizers are effective in photo dynamic therapy ${ }^{3-77}$ when the excited molecule transfers its excess energy to the ground state of the molecular oxygen ${ }^{3} \mathrm{O}_{2}$ producing the excited state singlet oxygen ${ }^{1} \mathrm{O}_{2}$. In this reaction (called Type II reaction) the photosensitizer goes through intersystem crossing from the excited state $S_{1}$ to the triplet state $T_{1}$ followed by regeneration of ground state $S_{0} \cdot{ }^{112}$ Thus, it is possible that the $810 \mathrm{fs}$ component is the intersystem crossing time. It is worth emphasizing that the $847 \pm 422 \mathrm{fs}$ component exists also in noncancerous tissue, indicating that intersystem crossing gives some contribution as a photo chemical pathway also in normal tissue, but the dynamics of the excited state is evidently dominated by the ultrafast component of $176 \mathrm{fs}$ (Table 2).

Although the primary mechanism of action of PDT is related to selective accumulation of photosensitizers in cancer tissue, ${ }^{113}$ it is not clear whether the photochemical pathways of energy dissipation upon light excitation are the same in the normal and cancerous tissue. The answer to this long standing question, which is a key challenge in clinical applications, will become clearer through analysis of the results presented above that can identify the pathways of photodynamic reactions in regions containing normal and malignant cells.

To obtain deeper inside into the physical meaning of the ultrafast component in the dynamics of the excited state of the noncancerous tissue let us first analyze a full picture of primary events in the time window up to $1 \mathrm{~ns}$. In view of the results presented so far one can see (Tables 1 and 2) that the ultrafast component is followed by the events occurring within a few picoseconds. The time components in the range of 1-7 ps obtained for $\mathrm{AlPcS}_{4}$ at different wavelengths are similar to that reported in the literature for many phthalocyanines. ${ }^{1,49,68}$ Savolainen et al. ${ }^{68}$ assigned the time constant of 2.5 ps to dielectric response of solvation. Rao et al. ${ }^{70}$ assigned the time constant of 3-5 ps to vibrational relaxation. Howe and Zhang ${ }^{55}$ assigned the time constant of $10 \mathrm{ps}$ to the lifetime for the $\mathrm{S}_{2} \rightarrow$ $S_{1}$ internal conversion. We assigned the time constants of $\mathrm{AlPcS}_{4}$ in solutions in the range $1-7 \mathrm{ps}$ to vibrational relaxation. ${ }^{1}$ Thus, the same assignment has been applied for the results presented in this paper for $\mathrm{AlPcS}_{4}$ at biological interfaces.

The time constants observed in solutions in the range of 150-500 ps have been assigned ${ }^{1,55}$ to decay from $S_{1}$ to the ground state. It is worth emphasizing that this slow component of a few hundred picoseconds $\left(345.81 \pm 107.87\right.$ ps for $\mathrm{AlPcS}_{4}$ in water) does not exist at biological interfaces. The slowest components in noncancerous tissue obtained from the excited state dynamics is $6.03 \pm 1.92 \mathrm{ps}$ and correspond to vibrational relaxation in the excited state. The vibrational relaxation of 5.63 \pm 5.49 ps in cancerous tissue is similar, but the excited state dynamics contains also the relatively slow component of 59.90 \pm 12.85 ps. Comparison of the time constants indicates that the return from the excited state $S_{1}$ to the ground state at the biological interface of noncancerous tissue is very fast in contrast to cancerous tissue. The short lifetimes of the excited state must be related to facilitated radiationless transitions that are usually provided by some special features of the potential energy surfaces such as the conical intersections. ${ }^{111}$ The mechanisms that lead to a decrease in the energy gap between the excited state and the ground state energy surfaces are related to the coupling between the electronic excited state and the vibrational modes. When the potential energy surfaces approach each other transitions are facilitated by their close proximity and the rate of nonradiative transitions increases. ${ }^{98}$ These very fast nonradiative processes with particularly short excited state lifetimes, which quickly dissipate the energy of the photon into small quanta of heat, represent the main channel that maintains the fundamental property of biological systems, photostability. Molecular structures responsible for harvesting of the solar energy must be photostable and resistant to photoinduced chemical changes and must find a specific way for recovery via relaxation and energy dissipation upon optical excitation. ${ }^{8}$ Many important features of biological sys tems ${ }^{111,114-116}$ can be explained with the idea of the conical intersection and avoided crossing. Worth and Cederbaum, for instance, proposed the conical intersection is an important feature for mediation of ultrafast electron transfers. ${ }^{114}$ Abramczyk ${ }^{98,115-119}$ has shown that the decrease in the energy gap between the excited state and the ground state energy surfaces due to the vibronic coupling plays a crucial role in understanding light energy dissipation in many biological systems, particularly in $\mathrm{H}$ bonded systems, and light initiated biological photoreceptors such as bacteriorhodopsin. Sobolew ski et al. ${ }^{120}$ have shown that conical intersections may be responsible for the mechanism of nonradiative decay of DNA bases.

An open question is how the biological environment affects the topography of the potential energy surfaces of the ground and excited state of the photosensitizer. Figure 13 illustrates the topographies with peaked and sloped conical intersections.

Figure 13a illustrates the situation when the crossing point is the lowest energy point on the excited state. In this case several channels may arise on the ground state from the crossing, resulting in various photoproducts. This kind of peaked intersection may result in degradation of the photosensitizer, which is bad for its photostability. At another topography (Figure 13b) the single point intersection may lead to efficient transitions from the excited state to the ground state with only one reaction product. On the other side, the sloped conical intersections that occur when more than two molecular vibrations are involved in the conical intersection may form a high dimensional 'seam' between the two states, rather than a single point. ${ }^{121}$ Some authors believe that ideal photostability goes through a sloped intersection ${ }^{122}$ with only one relaxation channel on the ground state leading back to reactant. In contrast, the others argue that sloped topographies direct the excited molecule toward the intersection less efficiently because 
a)
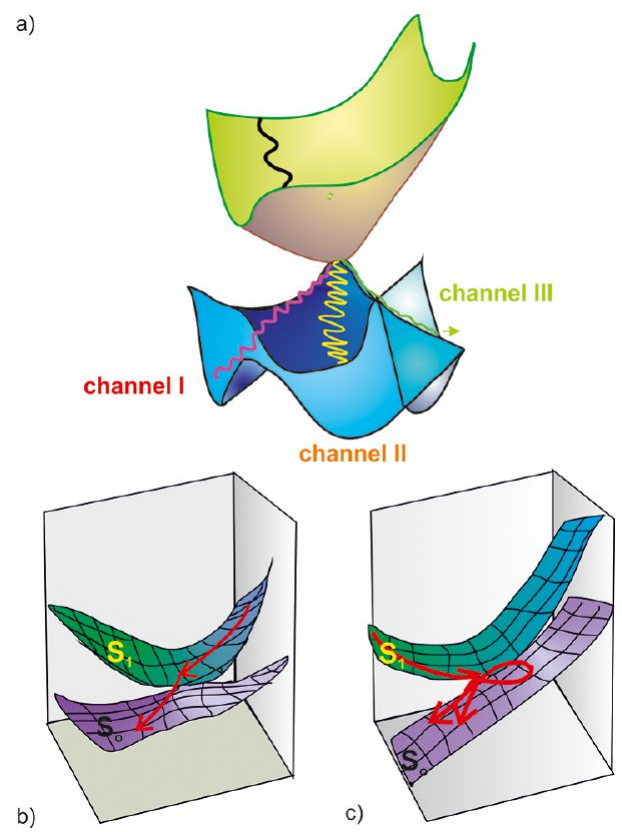

Figure 13. Peaked (a, b) and sloped conical intersections (c).

the molecule is more likely to 'miss' the intersection, and this topography leads to a wider variety of reaction products and lower photostability. ${ }^{121}$
In order to rationalize the experimental results obtained in this paper we propose the following picture for the primary events responsible for energy dissipation of the photosensitizer in noncancerous and cancerous tissues. Figure 14 illustrates the main channels of energy dissipation once upon light excitation of $\mathrm{AlPcS}_{4}$ in aqueous solution and at the interfacial regions of the biological tissue.

In aqueous solution (Figure 14c), after photon absorption, the excited state $S_{n}$ relaxes rapidly within 560 fs in the FranckCondon region followed by vibrational relaxation in the $S_{1}$ state with a time constant of 2.4 ps and return to the ground state $S_{0}$ via fluorescence with the excited state lifetime of 345 ps. The second channel of energy dissipation goes through intersystem crossing to the triplet state $T_{1}$ followed by return to the ground state $S_{0}$ via phosphorescence with the excited triplet state $\mathrm{T}_{1}$ lifetime of $28 \mathrm{ps}$. The phthalocyanine at biological interfaces of the human breast tissue does not relax via fluorescence. In cancerous tissue (Figure 14b) after photon absorption the excited state $S_{n}$ relaxes in the Franck-Condon region followed by intersystem crossing within 810 fs to the triplet state $T_{1}$ followed by return to the ground state $S_{0}$ via phosphorescence with the excited triplet state $T_{1}$ lifetime of 59.9 ps. The second channel goes through vibrational relaxation in the $S_{1}$ state with a time constant of 5.6 ps followed by the conical intersection to the ground state $S_{0}$ and vibrational relaxation in the ground state within 1.5 ps. In the noncancerous tissue (Figure 14a) the main channel is radiationless decay via conical intersection with time constants

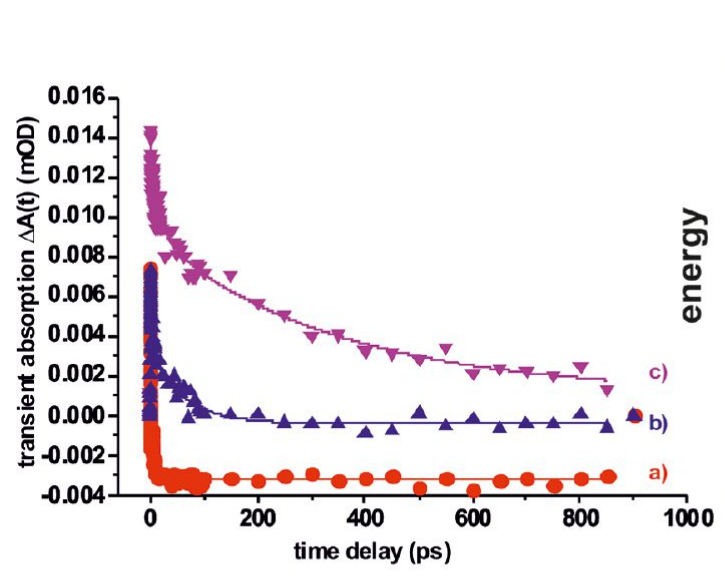

A) noncanceorus tissue

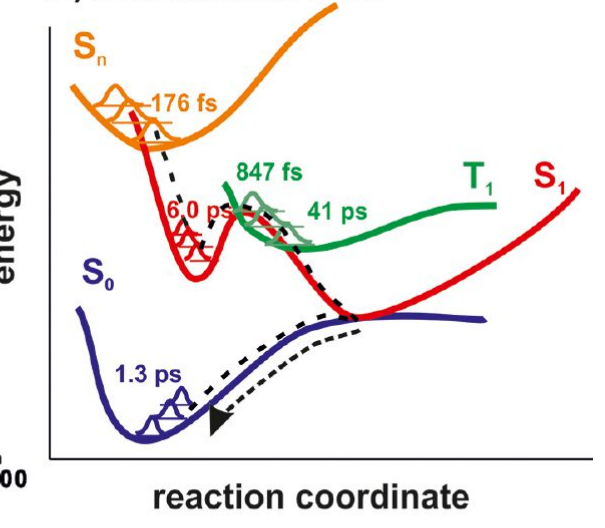

B) cancerous tissue

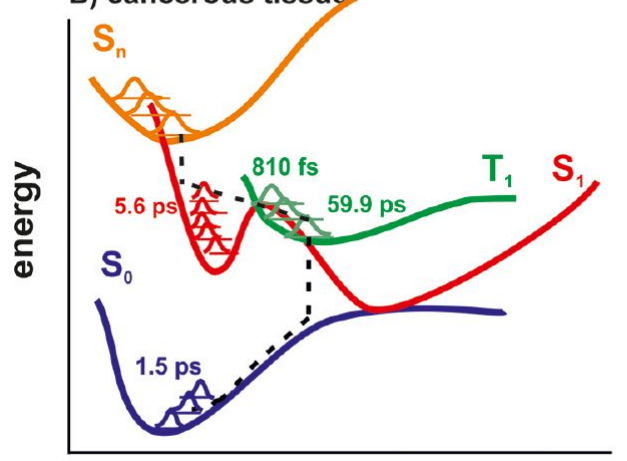

reaction coordinate

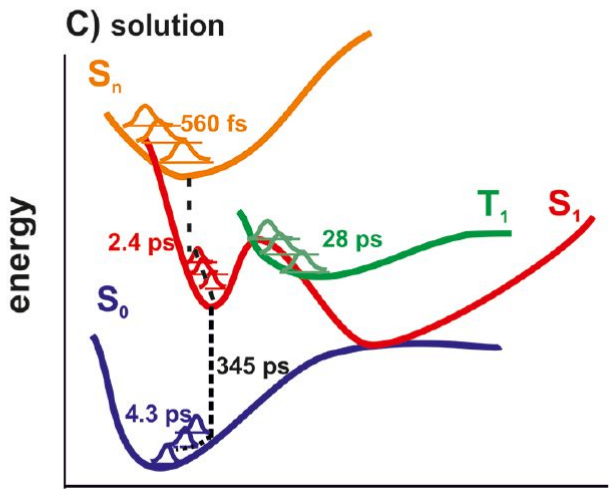

reaction coordinate

Figure 14. Comparison of the transient absorption signal $\Delta A(t)$ of $\mathrm{AlPcS}_{4}$ as a function of time delay in noncancerous $(\boldsymbol{O})$ (a) and cancerous $(\boldsymbol{\Delta})$ (b) human breast tissues (pumped at $677 \mathrm{~nm}$ and probed at $602 \mathrm{~nm}$ ) and aqueous solution ( $\boldsymbol{\nabla}$ ) (c) (concentration $10^{-3} \mathrm{M}$, pumped at $677 \mathrm{~nm}$, probed at $570 \mathrm{~nm}$ ). Excited state relaxation mechanisms in solution (A), normal (noncancerous) tissue (B), and cancerous human breast tissue (C). 

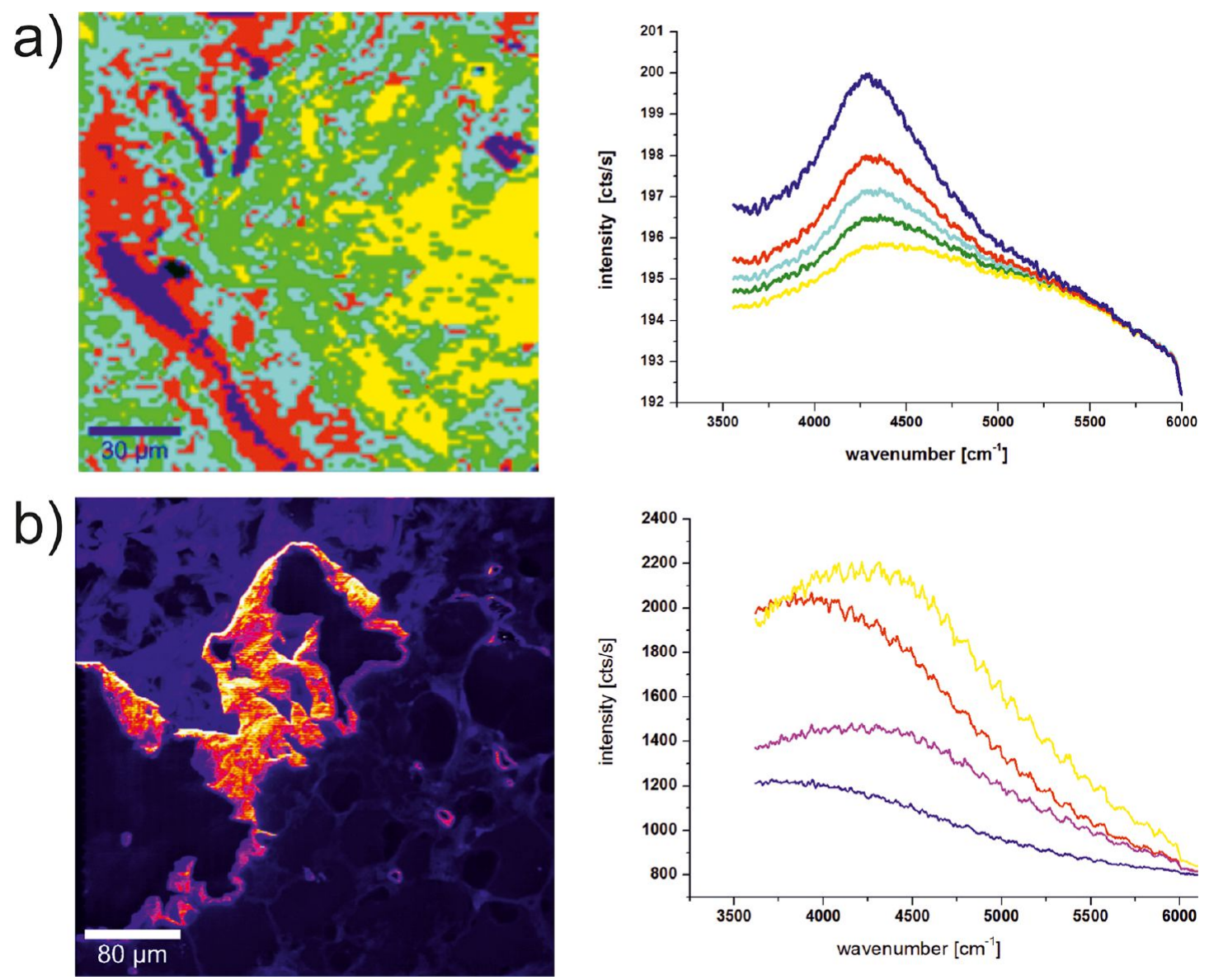

Figure 15. Fluorescence images and spectra of the cancerous (a) and normal (noncancerous) (b) breast tissues of patient P80.

of $176 \mathrm{fs}$ and 6 ps corresponding to wave packet dynamics in the Franck-Condon region of the $S_{1}$ state and vibrational relaxation of the excited state $S_{1}$, crossing the local barrier followed by relaxation to the conical intersection, respectively. The constant of $1.3 \mathrm{ps}$ along this pathway corresponds to vibrational relaxation in the ground state $S_{0}$. The second channel active in noncancerous tissue is intersystem crossing to the triplet state $T_{1}$ within $847 \mathrm{fs}$ and with time constants of 41 and 1.3 ps corresponding to the lifetime of $T_{1}$ and the ground vibrational relaxation state, respectively.

A question arises why the photochemical channels of energy dissipation of the photosensitizer at the interface of the normal and cancerous tissues are different. Although interactions at cellular surfaces involve large numbers of forces and molecular interactions, successful use of photosensitizers to achieve measurable biological responses, as presented in this report, indicates that it is indeed possible to probe the nano-bio interface experimentally. At first glance, interactions between the photosensitizer and cell surfaces seem to embody similar principles as those between molecules in hydrophobic and hydrophilic environments. Figure 4a demonstrates that normal breast tissue consists of fatty tissue with embedded ducts and blood vessels. Fatty tissue is hydrophobic as it is formed of glycerol monooleate (GMO) ${ }^{99}$ In contrast, cancerous tissue is dominated by epithelial cells, which produce milk and are lined with the ducts of the breast (Figure $4 \mathrm{~b}$ ). The surface of cancerous tissue is hydrophilic, ${ }^{100}$ and the level of various proteins is markedly elevated during disease development. We found ${ }^{100}$ that water amount confined in cancerous tissue is markedly higher than that in noncancerous tissue. Our results provide experimental evidence for the role played by the lipid profile and cell hydration as factors of particular significance in differentiation of noncancerous and cancerous breast tissues.

Thus, the hydrophilic phthalocyanine such as $\mathrm{AlPcS}_{4}$ at the hydrophilic cancerous breast tissue exhibits dynamics more similar to that in aqueous solution than that at the hydrophobic noncancerous breast tissue. The hydrophilic $\mathrm{AlPcS}_{4}$ phthalo cyanine displayed no binding with membranes formed of glycerol monooleate (GMO), ${ }^{123}$ which are the main con stituent of fatty tissues in the normal tissue. It indicates that hydrophilic photosensitizers interact weakly with the constit uents of normal breast tissue at the hydrophobic biological interface. It has been demonstrated ${ }^{124}$ that weak interactions between the hydrophilic and the hydrophobic molecules lead to interesting interfacial behavior. It has been shown that at the contact with the hydrophobic surface the interfacial hydrophilic molecule (water) shows very weak bonding character with other water molecules. A similar mechanism may drive weaker coupling between the hydrophilic molecules of the photo sensitizer resulting in less efficient coupling with the environ ment and a decrease in the energy barrier on the single excited state $S_{1}$ profile. The decrease in the height of the energy barrier may lead to a more efficient channel via conical intersection with radiationless decay.

This conclusion is supported by the fluorescence image for the photosensitizer $\mathrm{ZnPcS}_{4}$ at the interface of cancerous and noncancerous tissues presented in Figure 15. 
The colors represent different intensities of fluorescence of the Q band. The colors in the florescence images correspond to the colors of the fluorescence spectra. One can see that in cancerous tissue almost all regions of the tissue are fluorescent (Figure 15a). In contrast, in noncancerous tissue most regions under study do not reveal any fluorescence (Figure 15b).

\section{CONCLUSIONS}

The excited state dynamics of the tetrasulfonated aluminum phthalocyanine $\left(\mathrm{AlPcS}_{4}\right)$ have been studied at the biological interface of human breast tissue by Raman, IR, fluorescence, and pump-probe transient absorption laser spectroscopies, providing information about the events occurring in time scale ranging from femtoseconds to nanoseconds. We found that the dynamics in the interfacial regions of the biological tissue is markedly shorter than that in solution.

We found that photosensitizers responsible for harvesting of the light energy in biological tissue find their way for recovery through some special features of the potential energy surfaces such as conical intersections, which facilitate the rate of radiationless transitions. We found that the tetrasulfonated aluminum phthalocyanine interacts with normal (noncancer ous) breast tissue and cancerous tissue according to different pathways.

The dynamics in noncancerous tissue is dominated by radiationless decay at a conical intersection, in contrast to the dynamics in solutions, which is dominated by the fluorescence. The dynamics in cancerous tissue is dominated by the phosphorescence from the triplet state $\mathrm{T}_{1}$. We found that the dynamics of $\mathrm{AlPcS}_{4}$ reveals three time scales: 110-170 fs, $1-7$ ps, and 20-60 ps. The shortest time constants have been assigned to vibrational wavepacket dynamics in the FranckCondon region down to the local minimum of the excited state $S_{1}$, a few picosecond component has been assigned to vibrational relaxation in the ground and excited electronic states, and 20-60 ps components represent decay from the triplet state $T_{1}$ to ground state $S_{0}$.

\section{AUTHOR INFORMATION}

\section{Corresponding Author}

*Phone: +48 42 6313175, +48 42 6313188. Fax: +48 42684

00 43. E mail: abramczy@mitr.p.lodz.pl.

Notes

The authors declare no competing financial interest.

\section{ACKNOWLEDGMENTS}

This research work has been financed from funds for science in 2010-2012 as a research project "Preparation and implemen tation of new fields of studies in response to the needs of a contemporary labor market and requirements of knowledge based economy" UDA POKL.04.01.01. $00213 / 0800$ and partially from The National Science Center grant No. 2940/ B/T02/2011/40.

\section{REFERENCES}

(1) Jarota, A.; Tondusson, M.; Galle, G.; Freysz, E.; Abramczyk, H. Ultrafast Dynamics of Metal Complexes of Tetrasulphonated Phthalocyanines. J. Phys. Chem. A 2012, 116, 4000-4009.

(2) Brożek Płuska, B.; Jarota, A.; Kurczewski, K.; Abramczyk, H. Photochemistry of Tetrasulphonated Zinc Phthalocyanine in Water and DMSO Solutions by Absorption, Emission, Raman Spectroscopy and Femtosecond Transient Absorption Spectroscopy. J. Mol. Struct. 2009, 924-926, 338-346.
(3) Brożek Płuska, B.; Czajkowski, W.; Kurczewska, M.; Abramczyk, $\mathrm{H}$. Photochemistry of Tetrasulphonated Magnesium Phthalocyanine in Water and DMSO Solutions by Raman, Femtosecond Transient Absorption, and Stationary Absorption Spectroscopies. J. Mol. Liq. 2008, 141, 140-144.

(4) Abramczyk, H.; Brożek Płuska, B.; Kurczewski, K.; Kurczewska, M.; Szymczyk, I.; Krzyczmonik, P.; Błaszczyk, T.; Scholl, H.; Czajkowski, W. Femtosecond Transient Absorption, Raman and Electrochemistry Studies of Tetrasulphonated Copper Phthalocyanine in Water Solutions. J. Phys. Chem. A 2006, 110 (28), 8627-8636.

(5) Abramczyk, H.; Szymczyk, I. Peripheral Substituent and Solvent Effects on the Aggregation and Photochemical Properties of Copper(II) Phthalocyanine 3,4',4",4"' Tetrasulfonic Anion. J. Pure Appl. Chem. 2004, 76, 183-187.

(6) Abramczyk, H.; Szymczyk, I. Aggregation of Phthalocyanine Derivatives in Liquid Solutions and Human Blood. J. Mol. Liq. 2004, $110,51-56$.

(7) Abramczyk, H.; Szymczyk, I.; Waliszewska, G.; Lebioda, A. Photoinduced Redox Processes in Phthalocyanine Derivatives by Resonance Raman Spectroscopy. J. Phys. Chem. A. 2004, 108, 264274.

(8) Yang, Y. C.; Ward, J. R.; Seiders, R. P. Dimerization of Cobalt(II) Tetrasulfonated Phthalocyanine in Water and Aqueous Alcoholic solutions. Inorg. Chem. 1985, 24, 1765-1769.

(9) Ogawa, K.; Kinoshita, S.; Yonehara, H.; Nakahara, H.; Fukuda, K. Highly Ordered Monolayer Assemblies of Phthalocyanine Derivatives. J. Chem. Soc. Chem. Commun. 1989, 477-479.

(10) Kliesch, H.; Weitemeyer, A.; Muller, S.; Wohrle, D. Synthesis of Phthalocyanines with One Sulfonic Acid, Carboxylic Acid, or Amino Group. Liebigs Ann. Chem. 1995, 7, 1269-1273.

(11) Boyle, R. W.; van Lier, J. E. Synthesis of Novel Water Soluble Phthalocyanines for Use in the Photosensitized Inactivation of Cancer Cells and Viruses. Synlett 1993, 5, 351-353.

(12) Sharman, W. M.; Kudrevich, S. V.; van Lier, J. E. Novel Water Soluble Phthalocyanines Substituted with Phosphonate Moieties on the Benzo Rings. Tetrahedron Lett. 1996, 37, 5831-5834.

(13) Berg, K.; Moan, J. Mitotic Inhibition by Phenylporphines and Tetrasulfonated Aluminium Phthalocyanine in Combination with Light. Photochem. Photobiol. 1992, 56 (3), 333-339.

(14) Li, D. H.; Chen, X. L.; Fang, Y.; Xu, J. G. Determination of Nucleic Acids Based on Shifting the Association Equilibrium between Tetrasulfonated Aluminium Phthalocyanine and Acridine Orange. Analyst 2001, 126, 518-522.

(15) Ambroz, M.; Beeby, A.; MacRobert, A. J.; Simpson, M. C. S.; Svensen, R. K.; Philips, D. Preparative, Analytical and Fluorescence Spectroscopic Studies of Sulphonated Aluminium Phthalocyanine Photosensitizers. J. Phtochem. Pchotobiol. 1991, 9, 87-95.

(16) Nelson, J. S.; Liaw, L. H.; Orenstein, A.; Roberts, W. G.; Berns, M. W. Mechanism of Tumor Destruction Following Photodynamic Therapy with Hematoporphyrin Derivative, Chlorin, and Phthalocya nine. J. Natl. Cancer Inst. 1988, 80, 1599-605.

(17) Kawauchi, S.; Sato, S.; Morimoto, Y.; Kikuchi, M. Correlation Between Oxygen Consumption and Photobleaching During In Vitro Photodynamic Treatment with ATX S10 Na(II) Using Pulsed Light Excitation: Dependence of Pulse Repetition Rate and Irradiation Time. Photochem. Photobiol. 2004, 80, 216-233.

(18) Peavy, G. M.; Klein, M. K.; Newman, H. C.; Roberts, W. G.; Berns, M. W. The Use of Chloro Aluminum Sulfonated Pphthalocya nine as a Photosensitizer in the Treatment of Malignant Tumors in Dogs and Cats. Proc. SPIE 1991, 1424, 171.

(19) Mantareva, V.; Kussovski, V.; Angelov, I.; Wöhrle, D.; Dimitrov, R.; Popova, E.; Dimitrov, S. Non Aggregated Ga(III) Phthalocyanines in the Photodynamic Inactivation of Planktonic and Biofilm Cultures of Pathogenic Microorganisms. Photochem. Photobiol. Sci. 2011, 10 (1), 91-102.

(20) Mantareva, V.; Angelov, I.; Wöhrle, D.; Dogandjiska, V.; Dimitrov, R.; Kussovski, V. Water Soluble Phthalocyanine Complexes of $\mathrm{Ga}(\mathrm{III})$ and $\mathrm{In}(\mathrm{III})$ in the Photodynamic Inactivation of Pathogenic Fungus. Proc. SPIE 2010, 7747, 774712. 
(21) Feofanov, A.; Grichine, A.; Karmakova, T.; Kazachkina, N.; Pecherskih, E.; Yakubovskaya, R.; Luḱnanets, E.; Derkacheva, V.; Egret Charlier, M.; Vigny, P. Chelation with Metal is not Essential for Antitumor Photodynamic Activity of Sulfonated Phthalocyanines. Photochem. Photobiol. 2002, 75, 527-533.

(22) Aragón Aguilar, H.; Ramón Gallegos, E.; Arenas Huertero, J.; Contreras Ramos, A.; Cruz Orea, A.; Sosa Sánchez, J. L.; García Miranda, M. Kinetic of the Intraceullular Incorporation of New Phthalocyanines Systhesized in Mexico and its Potential as Photo sensiblizers in the Photodynamic Therapy. AIP Conf. Proc. 2008, 1032, 299-301.

(23) Gomes, E. R.; Almeida, R. D.; Carvalho, A. P.; Duarte, C. B. Nitric Oxide Modulates Tumor Cell Death Induced by Photodynamic Therapy Through a cGMP Dependent Mechanism. Photochem. Photobiol. 2002, 76 (4), 423-30.

(24) Peng, Q.; Moan, J. Correlation of Distribution of Sulphonated Aluminium Phthalocyanines with Their Photodynamic Effect in Tumour and Skin of Mice Bearing CaD2Mammary Carcinoma. Br. J. Cancer 1995, 72 (3), 565-74.

(25) Kessel, D.; Castelli, M.; Reiners, J. J., Jr. Apoptotic Response to Photodynamic Therapy Versus the Bcl 2 Antagonist HA14-1. Photochem. Photobiol. 2002, 76, 314-319.

(26) Strauss, W. S.; Gschwend, M. H.; Sailer, R.; Schneckenburger, H.; Steiner, R.; Ruck, A. Intracellular Fluorescence Behaviour of Meso Tetra(4 sulphonatophenyl)porphyrin During Photodynamic Treat ment at Various Growth Phases of Cultured Cells. J. Photochem. Photobiol. B 1995, 28, 155-61.

(27) Garcia, A. M.; Alarcon, E.; Muñoz, M.; Scaiano, J. C.; Edwards, A. M.; Lissi, E. Photophysical Behaviour and Photodynamic Activity of Zinc Phthalocyanines Associated to Liposomes. Photochem. Photobiol. Sci. 2011, 10 (4), 507-14.

(28) Lopez, T.; Ortiz, E.; Alvarez, M.; Navarrete, J.; Odriozola, J. A.; Martinez Ortega, F.; Páez Mozo, E. A.; Escobar, P.; Espinoza, K. A.; Rivero, I. A. Study of the Stabilization of Zinc Phthalocyanine in Sol Gel $\mathrm{TiO}_{2}$ for Photodynamic Therapy Applications. Nanomed.: Nanotechnol., Biol., Med. 2010, 6, 777-785.

(29) Makarov, D. A.; Kuznetsova, N. A.; Yuzhakova, O. A.; Savvina, L. P.; Kaliya, O. L.; Lukyanets, E. A.; Negrimovskii, V.; Strakhovskaya, M. G. Effects of the Degree of Substitution on the Physicochemical Properties and Photodynamic Activity of Zinc and Aluminum Phthalocyanine Polycations. Russ. J. Phys. Chem. A 2009, 83, 10441050.

(30) Chatlani, P. T.; Bedwell, J.; MacRobert, A. J; Barr, H.; Boulos, P. B.; Krasner, N.; Phillips, D.; Bown, S. G. Comparison of Distribution and Photodynamic Effects of Di Sulfonated and Tetra Sulfonated Aluminum Phthalocyanines in Normal Rat Colon. Photochem. Photobiol. 1991, 53 (6), 745-751.

(31) Sheng, C.; Pogue, B. W.; Wang, E.; Hutchins, J. E.; Hoopes, P. J. Assessment of Photosensitizer Dosimetry and Tissue Damage Assay for Photodynamic Therapy in Advanced stage Tumors. Photochem. Photobiol. 2004, 79 (6), 520-525.

(32) Belichenko, I.; Morishima, N.; Separovic, D. Caspase Resistant Vimentin Suppresses Apoptosis after Photodynamic Treatment with a Silicon Phthalocyanine in Jurkat Cells. Arch. Biochem. Biophys. 2001, 390 (1), 57-63.

(33) Halkiotis, K. N.; Manolopoulos, L. D.; Uzunoglou, N. K.; Yova, D. M Drug and Light Dose Dependence of PDT on Pancreatic Cancer Cells In Vitro. Proc. SPIE 1998, 3423, 427.

(34) Allison, R. R.; Bagnato, V. S.; Cuenca, R.; Downie, G. H.; Sibata, C. H. The Future of Photodynamic Therapy in Oncology. Future Oncol. 2006, 2 (1), 53-71.

(35) Vrouenraets, M. B.; Visser, G. W. M.; Snow, G. B.; van Dongen, G. A. M. S. Basic Principles, Applications in Oncology and Improved Selectivity of Photodynamic Therapy. Anticancer Res. 2003, 23, 505522.

(36) Henderson, B. W.; Dougherty, T. J. How Does the Photodymnamic Therapy Work? Photochem. Photobiol. 1992, 55, 145-57.
(37) Boyle, R. W.; Dolphin, D. Structure and Biodistribution Relationships of Photodynamic Sensitizers. Photochem. Photobiol. 1996, 64, 469-485.

(38) Brown, S. B.; Brown, E. A.; Walker, I. The Present and Future Role of Photodynamic Therapy in Cancer Treatment. Lancet Oncol. 2004, 5, 497-508.

(39) Wang, X. L.; Wang, H. W.; Yuan, K. H.; Li, F. L.; Huang, Z. Combination of Photodynamic Therapy and Immunomodulation for Skin Diseases-Update of Clinical Aspects. Photochem. Photobiol. Sci. 2011, 10, 704-711.

(40) Maduray, K.; Karsten, A.; Odhav, B.; Nyokong, T. J. In Vitro Photodynamic Effect of Aluminum Tetrasulfophthalocyanines on Melanoma Skin Cancer and Healthy Normal Skin Cells. Photo diagnosis. Photochem. Photobiol. B 2011, 103 (2), 98-104.

(41) Lui, H.; Anderson, R. R. Photodynamic Therapy in Dermatology. Shedding a Different Light on Skin Disease. Arch. Dermatol. 1992, 128 (12), 1631-1636.

(42) Stuchinskaya, T.; Moreno, M.; Cook, M. C.; Edwards, D. R.; Russell, D. A. Targeted Photodynamic Therapy of Breast Cancer Cells Using Antibody Phthalocyanine Gold Nanoparticle Conjugates. Photo chem. Photobiol. Sci. 2011, 10, 822-831.

(43) Whitacre, C. M.; Satoh, T. H.; Xue, L.; Gordon, N. H.; Oleinick, N. L. Photodynamic Therapy of Human Breast Cancer Xenografts Lacking Caspase 3. Cancer Lett. 2002, 179 (1), 43-49.

(44) Moura, V.; Lacerda, M.; Figueiredo, P.; Corvo, M. L.; Cruz, M. E. M.; Soares, R.; Pedroso de Lima, M. C.; Simões, S.; Moreira, J. N. Targeted and Intracellular Triggered Delivery of Therapeutics to Cancer Cells and the Tumor Microenvironment: Impact on the Treatment of Breast Cancer. Cancer Res. Treat. 2012, 133 (1), 61-73.

(45) Witjes, M. J.; Speelman, O. C.; Nikkels, P. G.; Nooren, C. A.; Nauta, J. M.; van der Holt, B.; van Leengoed, H. L.; Star, W. M.; Roodenburg, J. L. In Vivo Fluorescence Kinetics and Localisation of Aluminum Phthalocyanine Disulphonate in an Autologous Tumour Model. Br. J. Cancer 1996, 73 (5), 573-580.

(46) Austwick, M.; Woodhams, J. H.; Chalau, V.; Mosse, C. A.; Eliot, C.; Lovat, L. B.; MacRobert, A. J.; Bigio, I. J.; Bown, S. G. Optical Measurement of Photosensitizer Concentration In Vivo. JIOHS 2011, $4,97-111$.

(47) Taquet, J. P.; Frochot, C.; Manneville, V.; Barberi Heyob, M. Phthalocyanines Covalently Bound to Biomolecules for a Targeted Photodynamic Therapy. Curr. Med. Chem. 2007, 14 (15), 1673-87.

(48) Tokumaru, K. Phthalocyanines; Eds. Shirai, H.; Kobayashi, N. IPC, Tokyo, 1997, 170.

(49) Prasad, D. R.; Ferraudi, G. Photochemistry of Transition Metal Phthalocyanines. Monophotonic and Sequential Biphotonic Photo chemical Processes of Copper(II) tetrakis(N octadecylsulfamoyl) phthalocyanine in Nonaqueous. Media. Inorg. Chem. 1982, 21, 2967-2971.

(50) Muralidharan, S.; Ferraudi, G. Sequential Biphotonic Processes in Rhodium(III) Phthalocyanines. J. Phys. Chem. 1983, 87, 48774881.

(51) Ferraudi, G.; Muralidharan, S. Photochemistry of Transition Metal Phthalocyanines. Analysis of the Photochemical and Photo physical Properties of the Acido(phthalocyaninato)rhodium(III) Complexes. Inorg. Chem. 1983, 22, 1369-1374.

(52) Kaneko, Y.; Arai, T.; Sakarugi, H.; Tokumaru, K.; Pac, C. Effect of Excitation Wavelength on Photoreduction of Metal Free and Copper(II) 1,4,8,11,15,18,22,25 octabutoxyphthalocyanines with Trie thanolamine. J. Photochem. Photobiol. A 1996, 97, 155-162.

(53) Kaneko, Y.; Nishimura, Y.; Arai, T.; Sakuragi, H.; Tokumaru, K.; Matsunaga, D. UV Light and Red Light Chemistry of Metal lophthalocyanine: Wavelength Dependent Photochemical Reduction of Tetrasodium Salts of $\mathrm{Zn}$ (II) and $\mathrm{Cu}$ (II) Tetrasulphonatophthalo cyanines with Amines. J. Photochem. Photobiol. A. 1995, 89, 37-44.

(54) Kaneko, Y.; Nishimura, Y.; Takane, N.; Arai, T.; Sakuragi, H.; Tokumaru, K.; Kobayashi, N.; Matsunaga, D. Violet Emission Observed from Phthalocyanines. J. Photochem. Photobiol. A 1997, 106, 177-183. 
(55) Howe, I.; Zhang, J. Z. Ultrafast Studies of Excited State Dynamics of Phthalocyanine and Zinc Phthalocyanine Tetrasulfonate in Solution. J. Phys. Chem. A 1997, 101, 3207-3213.

(56) Ruckmann, I.; Zeug, A.; Herter, R.; Roder, B. On the Influence of Higher Excited States on the ISC Quantum Yield of Octa aL Alkyloxy Substituted Zn Phthalocyanine Molecules Studied by Non linear Absorption. Photochem. Photobiol. 1997, 66, 576-584.

(57) Chahraoui, D.; Valet, P.; Kossanyi, J. Fluorescence of Phthalocyanines: Emission from an Upper Excited State. Res. Chem. Intermed. 1992, 17, 219-232.

(58) Kobayashi, N.; Ashida, T.; Osa, T. Synthesis, Spectroscopy, Electrochemistry, and Spectroelectrochemistry of a Zinc Phthalocya nine with $\mathrm{D}_{2 \mathrm{~h}}$ Symmetry. Chem. Lett. 1992, 10, 2031-2031.

(59) Kobayashi, N.; Lever, A. B. P. Cation or Solvent Induced Supermolecular Phthalocyanine Formation: Crown Ether Substituted Phthalocyanines. J. Am. Chem. Soc. 1987, 109, 7433-7441.

(60) Kobayashi, N.; Lam, H.; Nevin, W. A.; Leznoff, C. C.; Koyama, T.; Monden, A.; Shirai, H. Synthesis, Spectroscopy, Electrochemistry, Spectroelectrochemistry, Langmuir Blodgett Film Formation, and Molecular Orbital Calculations of Planar Binuclear Phthalocyanines. J. Am. Chem. Soc. 1994, 116, 879-890.

(61) Kobayashi, N.; Togashi, M.; Osa, T.; Ishii, K.; Yamauchi, S.; Hino, H. Low Symmetrical Phthalocyanine Analogues Substituted with Three Crown Ether Voids and Their Cation Induced Super molecules. J. Am. Chem. Soc. 1996, 118, 1073-1085.

(62) Zhong, Q.; Wang, Z.; Liu, Y.; Zhu, Q.; Kong, F. The Ultrafast Intramolecular Dynamics of Phthalocyanine and Porphyrin Deriva tives. J. Chem. Phys. 1996, 105, 5377-5379.

(63) Strickler, S. J.; Berg, R. A. Relationship between Absorption Intensity and Fluorescence Lifetime of Molecules. J. Chem. Phys. 1962, 37, 814-822.

(64) Gilbert, A.; Baggott, J. Essentials of Molecular Photochemistry; Blackwell: Oxford, 1991; p 98.

(65) Rosenthal, I.; Krishna, C. M.; Riesz, P.; Ben Hur, E. The Role of Molecular Oxygen in the Photodynamic Effect of Phthalocyanines. Radiat. Res. 1989, 107, 136-142.

(66) Tokumaru, K. J. Photochemical and Photophysical Behaviour of Porphyrins and Phthalocyanines Irradiated with Violet or Ultraviolet Light. J. Porphyrins Phthalocyanines 2001, 5, 77-86.

(67) FitzGerald, S.; Farren, C.; Stanley, C. F.; Beeby, A.; Bryce, M. R. Protonation of Tetrasulfonated Zinc Phthalocyanine in Aqueous Acetonitrile Solution. Photochem. Photobiol. Sci. 2002, 1 (8), 581-587.

(68) Savolainen, J.; van der Linden, D.; Dijkhuizen, N.; Herek, J. L. J. Characterizing the Functional Dynamics of Zinc Phthalocyanine from Femtoseconds to Nanoseconds. Photochem. Photobiol. A 2008, 196, 99-105.

(69) Ho, Z. Z.; Peyghambarian, N. Femtosecond Dynamics in Organic Thin Films of Fluoro Aluminium Phthalocyanine. Chem. Phys. Lett. 1988, 148, 107-111.

(70) Rao, S. V.; Rao, D. N. Excited State Dynamics in Phthalocyanines Studied Using Degenerate Four Wave Mixing with Incoherent Light. J. Porphyrins Phthalocyanines 2002, 6, 233-237.

(71) Hosokawa, Y.; Yashiro, M.; Asahi, T.; Fukumura, H.; Masuhara, H. Femtosecond Laser Ablation Dynamics of Amorphous Film of a Substituted Cu Phthalocyanine. Appl. Surf. Sci. 2000, 154-155, 192195.

(72) Lam, M.; Lee, Y.; Deng, M.; Hsia, A. H.; Merrissey, K. A.; Yan, Ch.; Azzizudin, K.; Oleinick, N.; McCormick, T.; Cooper, K.; Baron, E. Photodynamic Therapy with the Silicon Phthalocyanine Pc 4 Induces Apoptosis in Mycosis Fungoides and Sezary Syndrome. Adv. Hematol. 2010, No. 896161.

(73) Hush, N. S.; Woolsey, I. S. The Electronic Absorption Spectra of Phthalocyanine Monomers and Dimers. Mol. Phys. 1971, 21, 465-474.

(74) Kobayashi, N.; Lever, A. B. P. Cation or Solvent Induced Supermolecular Phthalocyanine Formation: Crown Ether Substituted Phthalocyanines. J. Am. Chem. Soc. 1987, 109, 7433-7441.

(75) Kane, A. R.; Sullivan, J. F.; Kenny, D. H.; Kenney, M. E. The Nuclear Magnetic Resonance Spectra and the Electronic Spectra of
Some Silicon and Germanium Phthalocyanines. Inorg. Chem. 1987, 9, 1445-1448.

(76) Dhami, S.; Cosa, J. J.; Bishop, S. M.; Phillips, D. Photophysical Characterization of Sulfonated Aluminum Phthalocyanines in a Cationic Reversed Micellar System. Langmuir 1996, 12, 293-300.

(77) Ostler, R. B. Ph.D. Thesis, University of London, 1997.

(78) Dini, D.; Hanack, M. Phthalocyanines as Materials for Advanced Technologies: Some Examples. J. Porphyrins Phthalocyanines 2004, 8, 915-933.

(79) Jain, R. K. Delivery of Molecular and Cellular Medicine to Solid. Tumors. Adv. Drug Delivery Rev. 2001, 46, 149-168.

(80) Ball, D. J.; Mayhew, S.; Wood, S. R.; Griffiths, J.; Vernon, D. I.; Brown, S. B. A Comparative Study of the Cellular Uptake and Photodynamic Efficacy of Three Novel Zinc Phthalocyanines of Differing Charge. Photochem. Photobiol. 1999, 69 (3), 390-396.

(81) Pashkovskaya, A. A.; Perevoshchikova, I. V.; Maizlish, V. E.; Shaposhnikov, G. P.; Kotova, E. A.; Antonenko, Y. N. Interaction of Tetrasubstituted Cationic Aluminum Phthalocyanine with Artificial and Natural Membranes. Biochemistry (Moscow) 2009, 74 (9), 10211026.

(82) Rokitskaya, T. I.; Block, M.; Antonenko, Y. N.; Kotova, E. A.; Pohl, P. Photosensitizer Binding to Lipid Bilayers as a Precondition for the Photoinactivation of Membrane Channels. Biophys. J. 2000, 78 (5), 2572-2580.

(83) Yaku, H.; Murashima, T.; Miyoshi, D.; Sugimoto, N. Anionic Phthalocyanines Targeting G Quadruplexes and Inhibiting Telomerase Activity in the Presence of Excessive DNA Duplexes. Chem. Commun. 2010, 46, 5740-5742.

(84) De Filippis, M. P.; Dei, D.; Fantetti, L.; Roncucci, G. Synthesis of a New Water Soluble Octa Cationic Phthalocyanine Derivative for PDT. Tetrahedron Lett. 2000, 41, 9143-9147.

(85) Murphy, M. P. Selective Targeting of Bioactive Compounds to Mitochondria. Tibtech. 1997, 15, 326-330.

(86) Dougherty, T. J.; Gomer, Ch. J.; Henderson, B. W.; Jori, G.; Kessel, D.; Korbelik, M.; Moan, J.; Peng, Q. Photodynamic Therapy. INCI Cancer Spectrum 1998, 90, 889-905.

(87) McBride, G. Studies Expand Potential Uses of Photodynamic Therapy. JNCI Cancer Spectrum 2002, 94, 1740-1742.

(88) Ruoslahti, E. Specialization of Tumour Vasculature. Nat. Rev. Cancer 2002, 2, 83-90.

(89) Peng, Q.; Moan, J.; Nesland, J. M. Correlation of Subcellular and Intratumoral Photosensitizer Localization with Ultrastructural Features after Photodynamic Therapy. Ultrastruct. Pathol. 1996, 20, $109-129$.

(90) Rosenkranz, A. A.; Jans, D. A.; Sobolev, A. S. Targeted Intracellular Delivery of Photosensitizers to Enhance Photodynamic Efficiency. Immunol. Cell Biol. 2000, 78, 452-464.

(91) Moffatt, S. S. Nanoengineering Strategies for Antibody Nanoparticle Conjugates: Overview, Challenges and Promises. IJNN 2012, 3, 1-20.

(92) Dolmans, D. E. J. G. J.; Fukumura, D.; Jain, R. K. Photodynamic Therapy for Cancer. Nat. Rev. Cancer 2003, 3, 380-387.

(93) Locklin, J.; Shinbo, K.; Onishi, K.; Kaneko, F.; Bao, Z.; Advincula, R. C. Ambipolar Organic thin Film Transistor Like Behavior of Cationic and Anionic Phthalocyanines Fabricated Using Layer by Layer Deposition from Aqueous Solution. Chem. Mater. 2003, 15 (7), 1404-1412.

(94) Ma, G.; He, J.; Kang, C.; Tang, S. Excited State Dynamics Studies of Iron(III) Phthalocyanine Using Femtosecond Pump-Probe Techniques. Chem. Phys. Lett. 2003, 370, 293-299.

(95) Dayal, S.; Królicki, R.; Lou, Y.; Qiu, X.; Berlin, J. C.; Kenney, M. E.; Burda, C. Femtosecond Time Resolved Energy Transfer from CdSe Nanoparticles to Phthalocyanines. Appl. Phys. B: Laser Opt. 2006, 84, 309-315.

(96) Liu, Y.; Shigara, K.; Hara, M.; Yamada, A. Electrochemistry and Electrochromic Behavior of Langmuir Blodgett Films of Octakis Substituted Rare Earth Metal Diphthalocyanines. J. Am. Chem. Soc. 1992, 113, 440-443. 
(97) Ford, W. E.; Rihter, B. D.; Kenney, M. E.; Rodgers, M. A. Quenching of Naphthalocyanine Triplets by $\mathrm{O}_{2}$ : Application of the Sandros Equation. J. Photochem. Photobiol. 1989, 50, 277-282.

(98) Abramczyk, H. Mechanisms of Energy Dissipation and Ultrafast Primary Events in Photostable Systems: H bond, Excess Electron, Biological Photoreceptors. Vib. Spectr. 2012, 58, 1-11.

(99) Brozek Pluska, B.; Jablonska Gajewicz, J.; Kordek, R.; Abramczyk, H. Phase Transitions in Oleic Acid and in Human Breast Tissue as Studied by Raman Spectroscopy and Raman Imaging. J. Med. Chem. 2011, 54, 3386-3392.

(100) Abramczyk, H.; Brozek Pluska, B.; Surmacki, J.; Jablonska Gajewicz, J.; Kordek, R. Hydrogen Bonds of Interfacial Water in Human Breast Cancer Tissue Compared to Lipid and DNA Interfaces. JBC 2011, 2, 158-169.

(101) Abramczyk, H.; Brozek Pluska, B.; Surmacki, J.; Jablonska Gajewicz, J.; Kordek, R. The Label Free Raman Imaging of Human Breast Cancer. J. Mol. Liq. 2011, 164, 123-131.

(102) Abramczyk, H.; Brozek Pluska, B.; Surmacki, J.; Jablonska Gajewicz, J.; Kordek, R. Raman 'Optical Biopsy' of Human Breast Cancer. PBMB 2011, 108, 74-81.

(103) Abramczyk, H.; Surmacki, J.; Brozek Pluska, B.; Morawiec, Z.; Tazbir, M. The Hallmarks of Breast Cancer by Raman Spectroscopy. J. Mol. Struct. 2009, 924-926, 175-182.

(104) Brożek-Płuska, B.; Placek, I.; Kurczewski, K.; Morawiec, Z.; Tazbir, M.; Abramczyk, H. Breast Cancer Diagnostics by Raman Spectroscopy. J. Mol. Liq. 2008, 141, 145-148.

(105) Abramczyk, H.; Placek, I.; Brożek - Płuska, B.; Kurczewski, K.; Morawiec, Z.; Tazbir, M. Human Breast Tissue Cancer Diagnosis by Raman Spectroscopy. Spectrosc. Int. J. 2008, 22, 113-121.

(106) Tran Thi, T. H. Assemblies of Phthalocyanines with Porphyrins and Porphyrazines: Ground and Excited State Optical Properties. Coord. Chem. Rev. 1997, 160, 53-91.

(107) Nikolaitchik, A. V.; Korth, O.; Rodgers, M. A. J. Crown Ether Substituted Monomeric and Cofacial Dimeric Metallophthalocyanines. 1. Photophysical Studies of the Free Base, Zinc(II), and Copper(II) Variants. J. Phys. Chem. A 1999, 103, 7587-7596.

(108) Ma, G.; He, J.; Kang, Ch. H.; Tang, S. H. Excited State Dynamics Studies of Iron(III) Phthalocyanine Using Femtosecond Pump-Probe Techniques. Chem. Phys. Lett. 2003, 370, 293-299.

(109) Williams, V. S.; Mazumdar, S.; Armstrong, N. R.; Ho, Z. Z.; Peyghambarian, N. Femtosecond Excited State Dynamics in Fluoro and Chloroaluminum Phthalocyanine Thin Films. J. Phys. Chem. 1992, 96, 4500-4505.

(110) Speirs, N. M.; Ebenezer, W. J.; Jones, A. C. Observation of a Fluorescent Dimer of a Sulfonated Phthalocyanine. Photochem. Photobiol. 2002, 76, 247-251.

(111) Fournier, M.; Pepin, C.; Houde, D.; Ouellet, R; van Lier, J. E. W. Domcke, D. R. Yarkony, H. Koppel, Conical Intersections. Theory. Computation and Experiment. Adv. Ser. Phys. Chem. 2012, 17, 3-51.

(112) Allison, R. R; Downie, G. H.; Cuenca, R.; Hu, X. H.; Carter, J. H.; Childs; Sibata, C. H. Photosensitizers in Clinical PDT. Photodiagn. Photodyn. 2004, 1, 27-42.

(113) Gillenwater, A.; Jacob, R.; Richards Kortum, R. Fluorescence Spectroscopy: a Technique with Potential to Improve the Early Detection of Aerodigestive Tract Neoplasia. Head Neck 1998, 20 (6), 556-62.

(114) Worth, G. A.; Cederbaum, W. Mediation of Ultrafast Electron Transfer in Biological Systems by Conical Intersections. Chem. Phys. Lett. 2001, 338, 219-223.

(115) Abramczyk, H. IR $\nu_{s}(\mathrm{XH})$ Absorption Band Shape in $\mathrm{H}$ Bonded Complex. I. Theory. Chem. Phys. 1990, 144, 305-318.

(116) Abramczyk, H. IR $\nu_{\mathrm{s}}(\mathrm{XH})$ Absorption Band Shape of $\mathrm{H}$ Bonded Complex in Condensed Media. II. Numerical Calculations of the Profiles. Chem. Phys. 1990, 144, 319-326.

(117) Abramczyk, H. Absorption Spectrum of the Solvated Electron. 1. Theory. J. Phys. Chem. 1991, 95, 6149-6155.

(118) Abramczyk, H. Femtosecond Primary Events in Bacterio rhodopsin and its Retinal Modified Analogs: Revision of Commonly Accepted Interpretation of Electronic Spectra of Transient Inter mediates in the Bacteriorhodopsin Photocycle. J. Chem. Phys. 2004, 120, 11120-11132.

(119) Terentis, A.; Uji, L.; Abramczyk, H.; Atkinson, G. H. Primary Events in the Bacteriorhodopsin Photocycle: Torsional Vibrational Dephasing in the First Excited Electronic State. Chem. Phys. 2005, 313, $51-62$.

(120) Sobolewski, A. L.; Domcke, W. Hydrogen Transfer in Excitd Pyrrole Ammonia Clusters. Eur. Phys. J. D 2002, 20, 369-374.

(121) Martinez, T. J. Physical Chemistry: Seaming is Believing. Nature 2010, 467, 412-413.

(122) Hess, B.; de Visser, S. P.; Berendsen, H. J. C.; Olivucci, M.; Mark, A. E.; Robb, M. A. Photoactivation of the Photoactive Yellow Protein: Why Photon Absorption Triggers a Trans to Cis Isomer ization of the Chromophore in the Protein. J. Am. Chem. Soc. 2004, 126 (13), 4228-4233.

(123) Pashkovskaya, A. A.; Sokolenko, E. A.; Sokolov, V. S.; Kotova, E. A.; Antonenko, Y. N. Photodynamic Activity and Binding of Sulfonated Metallophthalocyanines to Phospholipid Membranes: Contribution of Metal Phosphate Coordination. Biochim. Biophys. Acta 2007, 1768, 2459-65.

(124) Moore, F. G.; Richmond, G. L. Integration or Segregation: How Do Molecules Behave at Oil/Water Interfaces? Acc. Chem. Res. 2008, 41, 739-748. 